OPEN ACCESS

Edited by:

Jian Yang,

Zhongshan Hospital, Fudan

University, China

Reviewed by:

Paulo M. Dourado,

University of São Paulo, Brazi

Ferdinando Iellamo,

University of Rome Tor Vergata, Italy

*Correspondence:

Jenna L. Taylor

taylor.jenna-lee@mayo.edu

Specialty section:

This article was submitted to General Cardiovascular Medicine,

a section of the journal

Frontiers in Cardiovascular Medicine

Received: 30 June 2021

Accepted: 31 July 2021

Published: 03 September 2021

Citation:

Taylor JL, Bonikowske AR and Olson TP (2021) Optimizing Outcomes

in Cardiac Rehabilitation: The

Importance of Exercise Intensity.

Front. Cardiovasc. Med. 8:734278.

doi: $10.3389 /$ fcvm.2021.734278

\section{Optimizing Outcomes in Cardiac Rehabilitation: The Importance of Exercise Intensity}

\author{
Jenna L. Taylor*, Amanda R. Bonikowske and Thomas P. Olson \\ Division of Preventative Cardiology, Department of Cardiovascular Medicine, Mayo Clinic, Rochester, MN, United States
}

Exercise based cardiac rehabilitation (CR) is recognized internationally as a class 1 clinical practice recommendation for patients with select cardiovascular diseases and heart failure with reduced ejection fraction. Over the past decade, several meta-analyses have generated debate regarding the effectiveness of exercise-based CR for reducing all-cause and cardiovascular mortality. A common theme highlighted in these meta-analyses is the heterogeneity and/or lack of detail regarding exercise prescription methodology within CR programs. Currently there is no international consensus on exercise prescription for $\mathrm{CR}$, and exercise intensity recommendations vary considerably between countries from light-moderate intensity to moderate intensity to moderate-vigorous intensity. As cardiorespiratory fitness [peak oxygen uptake $\left(\mathrm{VO}_{2}\right.$ peak)] is a strong predictor of mortality in patients with coronary heart disease and heart failure, exercise prescription that optimizes improvement in cardiorespiratory fitness and exercise capacity is a critical consideration for the efficacy of CR programming. This review will examine the evidence for prescribing higher-intensity aerobic exercise in CR, including the role of high-intensity interval training. This discussion will highlight the beneficial physiological adaptations to pulmonary, cardiac, vascular, and skeletal muscle systems associated with moderate-vigorous exercise training in patients with coronary heart disease and heart failure. Moreover, this review will propose how varying interval exercise protocols (such as short-duration or long-duration interval training) and exercise progression models may influence central and peripheral physiological adaptations. Importantly, a key focus of this review is to provide clinically-relevant recommendations and strategies to optimize prescription of exercise intensity while maximizing safety in patients attending CR programs.

Keywords: interval training, coronary artery disease, cardiovascular disease, heart failure, cardiorespiratory fitness, peak oxygen consumption, exercise prescription, progression

\section{INTRODUCTION}

Exercise-based cardiac rehabilitation (CR) is a class 1A recommendation for patients with select cardiovascular diseases (CVD) and heart failure with reduced ejection fraction (HFrEF), as it leads to significant improvements in exercise capacity, CVD risk profile, and reductions in hospital readmissions, cardiovascular (CV) events, and mortality (1-6). Compared with standard 
medical care, systematic reviews from 2004 (5) to 2011 (4) in coronary heart disease, showed that exercise-based CR reduced hospitalizations, CV mortality, and all-cause mortality by 31,26 , and $20 \%$, respectively $(4,5)$. However, over the past decade, results from RAMIT (Rehabilitation after Myocardial Infarction Trial) (7) and subsequent systematic reviews $(8,9)$ questioned the effectiveness of exercise-based CR for reducing recurrent CV events (7, 9), CV mortality (9), and all-cause mortality (7-9).

This generated substantial debate within the scientific community (10-12), with speculation that low exercise training intensity and dose may be responsible (13). Moreover, metaanalyses have shown significant heterogeneity and lack of detail regarding exercise prescription methodology within CR programs $(2,3)$. Currently there is no international consensus on exercise prescription or program duration for CR, and exercise intensity recommendations vary considerably between countries from light-moderate intensity (Australia, Japan), moderate intensity (United Kingdom, France), and moderatevigorous intensity (Canada, United States, South America, and other European countries) (14). Furthermore, studies from the United Kingdom have highlighted that in CR practice the actual exercise training intensities performed by patients, may not progress to the upper range of exercise intensity recommendations (13). Despite numerous publications outlining international CR practices and program characteristics from national registries or surveys, relatively few include data on exercise intensity prescription or implementation (15-18). This data is important to determine whether exercise training during $\mathrm{CR}$ is being prescribed and implemented effectively across international programs. There is a need to define internationally accepted standards in CR delivery and scientific evaluation $(2,3)$.

This review will examine the evidence for prescribing moderate-vigorous intensity aerobic exercise and high intensity interval training (HIIT) in CR programs, including beneficial physiological adaptations to the pulmonary, cardiac, vascular, and skeletal muscle systems in patients with CVD and heart failure (HF). Moreover, this review will discuss how increasing the duration of intervals and training volume may improve physiological adaptations; and will discuss practical applications and progression models to optimize exercise prescription in CR programs.

\section{Exercise Prescription in Cardiac Rehabilitation}

Methods for prescribing exercise intensity in CR vary internationally but can also be program-specific depending on the resources available. Objective methods for determining exercise intensity can include indices of peak exercise capacity, ventilatory thresholds, anaerobic threshold, or the myocardial ischemia threshold. These require availability of maximal exercise testing, preferably with cardiopulmonary gas analysis for intensities based on peak oxygen uptake ( $\mathrm{VO}_{2}$ peak), and/or ventilatory thresholds. In programs where maximal exercise testing is not available, subjective measures of exercise intensity including rating of perceived exertion (RPE) (19) or the talk test (TT) (20), are predominately used to guide exercise intensity.

\section{Indices of Peak Exercise Capacity}

The majority of guidelines on exercise training in CR recommend aerobic exercise prescription based on relative indices of peak exercise capacity. These include percentage of peak workload (Wpeak), percentage of peak heart rate (\%HRpeak), percentage of $\mathrm{VO}_{2}$ peak ( $\% \mathrm{VO}_{2}$ peak), percentage of $\mathrm{HR}$ reserve (\%HRR), or percentage of $\mathrm{VO}_{2}$ reserve $\left(\% \mathrm{VO}_{2} \mathrm{R}\right)(1,21)$. Reserve calculations are generally preferred for precise exercise intensity prescription given they also take into account the patient's resting values (22) and may be more appropriate for patients with chronotropic incompetence (23). In addition to issues with practicality of maximal exercise testing (due to cost, lack of expertise, technological resources, and/or medical supervision) $(24,25)$, limitations with using relative indices of peak exercise capacity can include patient failure to reach a near-maximal effort, subsequent dose adjustment and timing of rate-control medications, and the fact that $\mathrm{VO}_{2}$ peak or Wpeak are highly influenced by the ramp rate during the test $(1,26)$. Furthermore, a disadvantage with a workload-based approach is that progression is based on arbitrary increments, rather than a physiological change with improvements in exercise capacity (as HR does) (1).

\section{Ventilatory Thresholds}

An alternative approach to using indices of peak exercise capacity, is to relate exercise intensity to ventilatory thresholds. This approach requires cardiopulmonary gas analysis and is more commonly used for exercise prescription in European CR programs. Nomenclature of these thresholds remains controversial and methodologies to assess them are not universally accepted. The first ventilatory threshold (VT1) (also termed anaerobic threshold) is most widely known and represents the transition from a predominately aerobic metabolism to a point where blood lactate begins to accumulate and a greater reliance on anaerobic metabolism is needed for continued energy production $(1,27)$. At this point, ventilation (VE) accelerates to counterbalance and eliminate the excess carbon dioxide $\left(\mathrm{CO}_{2}\right)$ in the blood produced during the conversion of lactic acid to lactate (27). The second ventilatory threshold (VT2) (also termed respiratory compensation point, critical power, or lactate threshold) represents the exercise intensity at which blood lactate accumulates rapidly, excess $\mathrm{CO}_{2}$ can no longer be eliminated, and there is a disproportionate increase in $\mathrm{VE}$ relative to $\mathrm{CO}_{2}$ production (VCO2) $(1,28)$. The VT1 is commonly assessed using the $\mathrm{V}$-slope method (i.e., the departure of $\mathrm{VO}_{2}$ from a line of identity drawn through a plot of $\mathrm{VCO}_{2}$ vs. $\mathrm{VO}_{2}$ ) or the nadir (lowest point) of the $\mathrm{VE} / \mathrm{VO}_{2}$ to work rate relationship $(1,27)$. The VT2 is assessed as the nadir of $\mathrm{VE} / \mathrm{VCO}_{2}$ to work rate relationship $(1,28)$. Exercise training zones can then be extrapolated from these thresholds using a corresponding HR or workload, with light intensity below VT1, moderate intensity between VT1 and VT2, and high intensity above VT2 (1). There are several disadvantages with using threshold-based exercise prescription. There can be substantial within-subject variability from two consecutive tests (29), a high variation between observers and sites (30), and the reproducibility of VT2 is not well established in patients with CVD (1). Furthermore, VT thresholds cannot be directly translated to constant-load exercise 
due to slowed $\mathrm{VO}_{2}$ kinetics and delay in $\mathrm{VO}_{2}$ response to the imposed work $(1,31)$, which is exaggerated in patients with CVD and HF (32-34).

\section{Subjective Measures}

Regardless of whether objective measures of effort (such as $\mathrm{HR}$ or $\mathrm{VO}_{2}$ ) are available, subjective measures of effort (e.g., RPE or TT) should be used as an adjunct in CR settings, particularly for patients who have difficulty obtaining a reliable or meaningful exercise-related HR (e.g., patients with atrial fibrillation, pacemakers, chronotropic incompetence, heart transplant, or patients receiving beta blockade therapy) (23, 28). Subjective measures can also be useful for comparing the perceived effort across exercise modalities (28). The Borg 620 RPE scale is a widely used instrument to measure exercise intensity, by asking patients to self-report their perceived effort of exercise on a scale of 6 (no exertion at all) to 20 (very, very hard) (19). It is a practical, validated, and effective method for prescribing and monitoring exercise intensity in patients with CVD $(35,36)$ and HF $(37,38)$, and is not influenced by betablocker medication (38). Limitations of using the RPE scale may include the influence of psychological factors or environmental conditions (28), difficulties in patients with impaired vision (23), or use during outdoor exercise (24). Lack of familiarity with exercise training, fitness level, age, gender, education level, and use of diuretics have also been reported to influence RPE (3941). It is imperative that patients are educated on correct use of the RPE scale, anchored to sensations of extremely hard/maximal and no exertion at all, and representing an integrated rating of muscular and cardiovascular sensations $(19,26)$. The TT is another practical tool for prescribing exercise intensity, that has shown to be valid and reliable in patients with CVD (20). Physiologically, it is based on the swift increase in breathing above VT2 (or lactate threshold) that causes difficultly in comfortable talking during exercise (1), and can therefore help to identify the boundary between moderate and vigorous intensity exercise (24). The TT is not a practical tool for customizing interval training protocols with short durations $(<1 \mathrm{~min})$ or at very high intensity ( $>95 \%$ HRpeak) (20), however further research into its use for longer duration HIIT protocols of 85$95 \%$ HRpeak [e.g., $4 \times 4$ min protocol $(26,42)$ ] would be of interest. For home-based HIIT, Wisløff et al. instructed patients with HF to complete a $4 \mathrm{~min}$ interval at an intensity where "they are breathing heavily and talking becomes uncomfortable" (43), which corresponded to an RPE of $17 \pm 1$ and $93 \pm 3 \%$ of HRpeak (44).

\section{Summary}

Recent guidelines have suggested that while subjective measures can be a practical method to prescribe exercise intensity, they should be used as an adjunct rather than alternative to objective methods (1). Furthermore, concerns have been raised that exercise training intensity based on results of indirect, submaximal exercise testing (e.g., $6 \mathrm{~min}$ walk test, incremental shuttle walk test), which do not rigorously evaluate the cardiorespiratory system, may result in under-prescription of exercise intensity and reduced effectiveness of CR programs (12).
Where available, $\mathrm{VO}_{2}$ peak and HRpeak should be determined from a maximal cardiopulmonary exercise test, during which the patient has taken prescribed HR-modulating medications. If a maximal exercise test is not feasible, a new predictive equation combining age and $\mathrm{HR}$ measured during a $200 \mathrm{~m}$ fast walk test (45), has shown good correlation with HRpeak measured during a maximal exercise test. In this case, accounting for age and HR response to a submaximal test may be more predictive of an accurate HRpeak than relying on age-predicted equations for patients with (46) and without beta-blockade $(47,48)$. However, the equation for patients with beta-blockade (46) accounts for resting $\mathrm{HR}$ and test mode in addition to age (46).

\section{Is There a Benefit for Prescribing Higher Intensity Exercise?}

Definition of Exercise Intensity Ranges and Protocols

Classifications of exercise intensity by the American College of Sports Medicine (ACSM) (49) and European Association of Preventative Cardiology (EAPC) (1) are outlined in Table 1. As exercise performed at a vigorous to high intensity cannot be sustained for long periods. HIIT can be a more feasible method by alternating bouts of high intensity exercise with recovery bouts of lower intensity exercise or no exercise. There has been a large amount of scientific interest regarding HIIT in patients with CVD and HF, mostly comparing its effectiveness to moderate intensity continuous training (MICT). Sprint interval training (SIT) involves intense "all-out" or supramaximal efforts (i.e., workloads greater than $\mathrm{VO}_{2}$ peak or peak power output) with typically shorter bouts ( $<45 \mathrm{~s})(50)$. Although HIIT involves near-maximal intensities, efforts are still submaximal (i.e., workloads below $\mathrm{VO}_{2}$ peak or peak power output), and therefore HIIT has been considered more appropriate for use in clinical populations than SIT (51). The terminology of HIIT and MICT are preferred given they provide a description of intensity (51). However, aerobic interval training (AIT) and aerobic continuous training (ACT), respectively are alternative terminology frequently used within with the literature. Common intensity prescription of HIIT and MICT used in patients with coronary artery disease (CAD) and HF are outlined in Table 2, devised from studies included in reviews by Pattyn et al. (52) and Taylor et al. (53). While these ranges outline the HIT and MICT prescriptions for the majority of studies in cardiac patients, two studies have prescribed notably higher intensities for MICT in CAD including 60-80 \% $\mathrm{VO}_{2}$ peak $(54,55)$ and $65-85 \%$ HRpeak (56). There are also three studies that prescribed notably lower intensity for HIIT, with one in CAD (50 \% peak workload from a steep ramp test) (57), and two in HF with 50-80 \% maximal power (58) and 50-75\% of $\mathrm{VO}_{2}$ peak (59).

\section{Influence of Exercise Intensity on CVD and Mortality}

Numerous studies investigating all-cause mortality in healthy populations, have demonstrated that higher intensity exercise may induce larger health benefits than low or moderate intensity exercise. Furthermore, benefits with high intensity exercise can be achieved in substantially less time than MICT. The Hunt Study (60) demonstrated that one single bout of high intensity exercise reduced all-cause and CV mortality to a similar or 
TABLE 1 | Classification of aerobic exercise intensity.

\begin{tabular}{|c|c|c|c|c|c|c|}
\hline \multicolumn{3}{|c|}{ ACSM Guidelines (49) } & \multicolumn{4}{|c|}{ EAPC and ESC Guidelines (1) } \\
\hline Intensity & $\mathrm{VO}_{2}$ and $\mathrm{HR}$ & RPE & Intensity & $\mathrm{VO}_{2}$ and $\mathrm{HR}$ & RPE & Training zone \\
\hline Light & $\begin{array}{l}37-45 \% \mathrm{VO}_{2} \max \\
57-63 \% \mathrm{HRmax} \\
30-39 \% \mathrm{HRR}\end{array}$ & $9-11$ & Low & $\begin{array}{l}<40 \% \mathrm{VO}_{2} \max \\
<55 \% \mathrm{HRmax} \\
<40 \% \mathrm{HRR}\end{array}$ & $10-11$ & Aerobic \\
\hline Moderate & $\begin{array}{l}46-63 \% \mathrm{VO}_{2} \max \\
64-76 \% \mathrm{HRmax} \\
40-59 \% \mathrm{HRR}\end{array}$ & $12-13$ & Moderate & $\begin{array}{l}\text { 40-69 \% } \mathrm{VO}_{2} \max \\
55-74 \% \mathrm{HRmax} \\
40-69 \% \mathrm{HRR}\end{array}$ & $12-13$ & Aerobic \\
\hline Vigorous & $\begin{array}{l}64-90 \% \mathrm{VO}_{2} \max \\
77-95 \% \mathrm{HRmax} \\
60-89 \% \mathrm{HRR}\end{array}$ & $14-17$ & High & $\begin{array}{l}70-85 \% \mathrm{VO}_{2} \max \\
75-90 \% \mathrm{HRmax} \\
70-85 \% \mathrm{HRR}\end{array}$ & $14-16$ & Aerobic + lactate \\
\hline Near-maximal to maximal & $\begin{array}{l}>90 \% \mathrm{VO}_{2} \max \\
>95 \% \mathrm{HRmax} \\
>89 \% \mathrm{HRR}\end{array}$ & $>17$ & Very high & $\begin{array}{l}>85 \% \mathrm{VO}_{2} \max \\
>90 \% \mathrm{HRmax} \\
>85 \% \mathrm{HRR}\end{array}$ & $17-19$ & Aerobic + lactate + anerobic \\
\hline
\end{tabular}

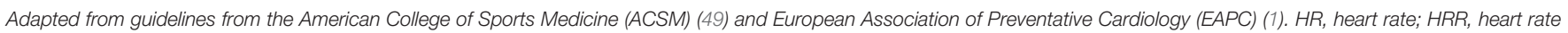
reserve; $R P E$, rating of perceived exertion on 6-20 Borg scale (19); $\mathrm{VO}_{2}$, oxygen uptake.

TABLE 2 | Common intensity prescriptions for HIIT and MICT.

\begin{tabular}{|c|c|c|c|c|}
\hline \multirow[b]{2}{*}{ Training protocol } & \multicolumn{2}{|c|}{ Patients with CAD } & \multicolumn{2}{|c|}{ Patients with HF } \\
\hline & $\mathrm{HR}$ or $\mathrm{VO}_{2}$ & Other measures & $\mathrm{HR}$ or $\mathrm{VO}_{2}$ & Other measures \\
\hline \multirow[t]{3}{*}{ MICT } & 60-75 \%HRpeak & RPE 11-14 & 60-75 \%HRpeak & 50-75 \%РPО \\
\hline & 60-85 \%HRR & 50-65 \%PPO & 45-60 \%HRR & 90-100 \%VT1 \\
\hline & $50-60 \% \mathrm{VO}_{2}$ peak & $100-110 \% \mathrm{VT} 1$ & $60-70 \% \mathrm{VO}_{2}$ peak & \\
\hline \multirow[t]{3}{*}{ HIIT } & 80-100 \%HRpeak & RPE 15-18 & 80-95 \%HRpeak & 90-100 \%РPO \\
\hline & 80-95 \%HRR & 90-110 \%PPO & $75-80 \% \mathrm{HRR}$ & \\
\hline & 80-90 \% $\mathrm{VO}_{2}$ peak & $100 \%$ VT2 or \%RCP & $70-80 \% \mathrm{VO}_{2}$ peak & \\
\hline
\end{tabular}

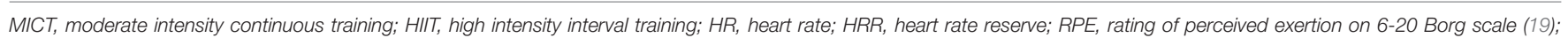
$V \mathrm{O}_{2}$, oxygen uptake; VT1, first ventilatory threshold; VT2, second ventilatory threshold; PPO, peak power output; RCP, respiratory compensation point.

greater degree than several hours of MICT. Similarly, Wen et al. (61), demonstrated the superior or time-efficient advantages of vigorous intensity exercise, with similar health benefit to MICT in half the weekly exercise time, or double the health benefit to MICT with the same weekly exercise time. Furthermore, studies have shown the proportion of vigorous activity has an inverse dose-response relationship with all-cause mortality in people with and without CVD, calling for physical activity (PA) guidelines to endorse participation in vigorous activity $(62,63)$. Finally, several studies have also shown an inverse association between exercise intensity and incidence of coronary heart disease in men independent of total exercise volume $(64,65)$, however the association of exercise intensity is less clear in women $(66,67)$.

\section{Influence of Exercise Intensity on Cardiorespiratory Fitness}

Cardiorespiratory fitness (assessed as $\mathrm{VO}_{2}$ peak) reflects an integrated ability to transport oxygen $\left(\mathrm{O}_{2}\right)$ around the body, encompassing pulmonary function, cardiac function (systolic and diastolic), ventricular-arterial coupling, vascular function, and the ability of muscle cells to receive and use $\mathrm{O}_{2}$ (68). There is extensive evidence that $\mathrm{VO}_{2}$ peak is a strong predictor of future $\mathrm{CV}$ events and mortality, and even modest increments in $\mathrm{VO}_{2}$ peak can be clinically meaningful in patients with CAD and HF (69-71). A landmark study by Kavanagh et al. in 12,169 CAD patients referred for CR, found that each $1.0 \mathrm{~mL} / \mathrm{kg} / \mathrm{min}$ increment in $\mathrm{VO}_{2}$ peak was associated with a $9 \%$ increase in survival. Moreover, Keteyian et al. (72) found an increased survival of $15 \%$ per $1.0 \mathrm{~mL} / \mathrm{kg} / \mathrm{min}$ increment of $\mathrm{VO}_{2}$ peak in patients with CAD. A study by Mikkelsen et al. (69) including 1,561 cardiac patients (predominately with CAD; $84 \%$ ), found that for every $1.0 \mathrm{~mL} / \mathrm{kg} / \mathrm{min}$ improvement in $\mathrm{VO}_{2}$ peak during $\mathrm{CR}$, there was a $21 \%$ reduction in $\mathrm{CV}$ events and a $13 \%$ reduction in all-cause mortality. In patients with HF, the HF-ACTION trial (71) showed that every $6 \%$ improvement in $\mathrm{VO}_{2}$ peak (adjusted for other factors) was associated with an $8 \%$ lower risk of $\mathrm{CV}$ mortality and HF hospitalization, and a $7 \%$ lower risk of allcause mortality. In a large meta-regression analysis examining 55 trials of either HIIT or MICT compared with control in patients with CAD and HF, Uddin et al. (73) demonstrated that exercise intervention intensity was the greatest predictor of $\mathrm{VO}_{2}$ peak 
post CR, even when including age, sex, and baseline fitness level in the multivariable regression model. Furthermore, each $10 \%$ increase in exercise intensity (as $\% \mathrm{VO}_{2}$ peak or \%HRpeak) was associated with a $1.0 \mathrm{~mL} / \mathrm{kg} / \mathrm{min}$ increase in $\mathrm{VO}_{2}$ peak post CR. This is supported by Mitchell et al. (74) in patients attending $\mathrm{CR}$ for any indication, finding the greatest improvements in $\mathrm{VO}_{2}$ peak with vigorous intensity exercise $(5.5 \mathrm{~mL} / \mathrm{kg} / \mathrm{min})$, followed by moderate-vigorous intensity $(4.9 \mathrm{~mL} / \mathrm{kg} / \mathrm{min})$, and then moderate intensity exercise $(4.1 \mathrm{~mL} / \mathrm{kg} / \mathrm{min})$. In contrast, a meta-analysis in patients with HF that adjusted for total exercise expenditure (75) found duration and frequency of exercise sessions to be greater predictors of $\mathrm{VO}_{2}$ peak improvement than exercise intensity, however this review excluded interval training studies (including HIIT). Another meta-analysis in patients with HF that included HIIT studies (76), found high intensity ( $\geq 90 \%$ HRpeak or $\geq 85 \%$ HRR) but not vigorous intensity exercise (70-90 \%HRpeak; 60-85 \%HRR) produced larger improvements in $\mathrm{VO}_{2}$ peak compared with moderate intensity exercise (55-80 \%HRpeak; 50-60 \%HRR) with gains of $3.3,2.3$, and $2.2 \mathrm{~mL} / \mathrm{kg} / \mathrm{min}$, respectively. Low intensity exercise (40-55\%HRpeak; 20-40\%HRR) produced the smallest improvement $(1.0 \mathrm{~mL} / \mathrm{kg} / \mathrm{min})(76)$.

Studies based in the United Kingdom (UK) have found smaller improvements in cardiorespiratory fitness $[\sim 0.7-0.8$ metabolic equivalents (METs)] compared with international programs ( 1.5 METs) (77). The UK guidelines for CR programs typically recommend exercise of a moderate intensity (40$70 \%$ HRR), compared with moderate-high intensity exercise recommendations in Canada (40-85 \%HRR), United States (40$80 \% \mathrm{VO}_{2}$ peak) and other European countries $\left(40-80 \% \mathrm{VO}_{2}\right.$ peak; up to $90 \%$ HRpeak) (14). Furthermore, a UK study by Nichols et al. (13) reported that the peak exercise training intensities achieved (46-54\%HRR) did not progress to the upper range of the UK exercise prescription targets (40-70\%HRR), and that after 8 weeks the exercise duration achieved $(23 \mathrm{~min})$ only marginally exceeded the minimum recommended duration of $20 \mathrm{~min}$. Therefore, lower exercise intensity and volume have been reported as contributors to the smaller $\mathrm{VO}_{2}$ peak improvements in CR programs within the UK $(13,78)$. This may also be typical of CR programs in other countries with low-moderate intensity guidelines, with potential to reduce the overall effectiveness of CR.

There have been several meta-analyses comparing HIIT with MICT on cardiorespiratory fitness as $\mathrm{VO}_{2}$ peak. Weston et al. (51) examined 10 studies in patients with cardiometabolic disease and found that HIIT improved $\mathrm{VO}_{2}$ peak by $19 \%$ compared to $10 \%$ with MICT (mean difference $=3.0 \mathrm{~mL} / \mathrm{kg} / \mathrm{min}$ ). In patients with CAD, several meta-analyses have shown a superior effect of HIIT compared with MICT on $\mathrm{VO}_{2}$ peak improvement, with a mean difference $1.3-1.8 \mathrm{~mL} / \mathrm{kg} / \mathrm{min}$ (52, 79-82). Pattyn et al. found HIIT protocols that were isocaloric with MICT were more likely to show superiority over MICT $(+2.1 \mathrm{~mL} / \mathrm{kg} / \mathrm{min})$ compared with HIIT protocols that were a lower energy expenditure to MICT $(+0.2 \mathrm{~mL} / \mathrm{kg} / \mathrm{min})$ (52). Furthermore, Way et al. (83) demonstrated that although women tend to experience lower absolute improvements in $\mathrm{VO}_{2}$ peak with HIIT than men, they have similar relative improvements in $\mathrm{VO}_{2}$ peak (83). The
FITR Heart Study, a recently published pragmatic trial in 93 CAD patients using RPE as the primary method of exercise prescription (36), also demonstrated a superior effect of HIIT compared with MICT during a 4-week CR program, with a mean difference in $\mathrm{VO}_{2}$ peak improvement of $1.7 \mathrm{~mL} / \mathrm{kg} / \mathrm{min}$. In contrast to this trial and previous meta-analyses, the SAINTEXCAD multicenter trial in 200 patients with CAD, found both HIIT and MICT produced equally substantial improvements in $\mathrm{VO}_{2}$ peak (23 and $20 \%$, respectively) during a 12-week CR program (84). A noteworthy consideration with this trial, was the higher training intensity of the MICT group (average training intensity of $80 \%$ HRpeak), compared with previous trials that prescribed training intensity at 65-75\%HRpeak (42, 85). Although the SAINTEX-CAD had designed MICT to be prescribed at 70-75 \%HRpeak, patients were not restrained from exercising at higher intensities. Therefore, results of the SAINTEX-CAD study suggest that continuous training may be equally effective to HIIT for improving $\mathrm{VO}_{2}$ peak, when performed at a vigorous intensity. In patients with $\mathrm{HF}$, meta-analyses have also found a superior effect of HIIT compared with MICT on $\mathrm{VO}_{2}$ peak improvement, with a mean difference $1.0-2.4 \mathrm{~mL} / \mathrm{kg} / \mathrm{min}(52,82,86,87)$. However, the large multicenter SMARTEX HF study (88) in 261 patients with HFrEF, found similar improvements in $\mathrm{VO}_{2}$ peak with HIIT $(1.4 \mathrm{~mL} / \mathrm{kg} / \mathrm{min})$ and MICT $(0.8 \mathrm{~mL} / \mathrm{kg} / \mathrm{min})$ compared with an exercise guidelines group that showed a decrease in $\mathrm{VO}_{2}$ peak $(-1.0 \mathrm{~mL} / \mathrm{kg} / \mathrm{min})$. While median training intensity for HIIT was $90 \%$ HRpeak (interquartile range 88-92\%) and $77 \%$ HRpeak (interquartile range $74-82 \%$ ) for MICT, $51 \%$ of HIIT patients exercised at a lower intensity than prescribed and $80 \%$ of MICT participants trained at a higher intensity than the protocol prescribed (88). In 180 patients with preserved ejection (HFpEF), the multicenter OptimEX-Clin study (89) found neither HIIT or MICT met the prespecified minimal clinically important improvement in $\mathrm{VO}_{2}$ peak $(2.5 \mathrm{~mL} / \mathrm{kg} / \mathrm{min})$ compared with a PA guidelines control group. However, HIIT and MICT showed similar increases in $\mathrm{VO}_{2}$ peak of 1.1 and $1.6 \mathrm{~mL} / \mathrm{kg} / \mathrm{min}$, respectively, over the 3 -month supervised training (89). The meta-analysis by Pattyn et al. (52), also found no differences between HIIT and MICT for improvement of $\mathrm{VO}_{2}$ peak in the HFpEF sub-analysis.

\section{Influence of Exercise Intensity on Other Cardiometabolic Parameters}

Exercise intensity appears to have a significant influence on increasing exercise capacity at VT1. An early study by Jensen et al. in patients with CAD (90), found high intensity continuous training was superior to low intensity training for improving $\mathrm{VO}_{2}$ at VT1. Furthermore, the meta-analysis by Pattyn et al. (52) in both $\mathrm{CAD}$ and HF patients, found greater improvements in $\mathrm{VO}_{2}$ at VTI after HIIT compared with MICT (mean difference of $0.9 \mathrm{~mL} / \mathrm{kg} / \mathrm{min}$ ). This is important as the improved ability to use $\mathrm{O}_{2}$ aerobically may translate into improved performance of daily living activities (52). Pattyn et al. (52) also found a greater improvement in HRpeak with HIIT compared with MICT, and a trend for greater improvement in peak $\mathrm{O}_{2}$ pulse and $\mathrm{O}_{2}$ uptake efficiency slope (OUES) favoring HIIT. Other 
cardiorespiratory parameters (e.g., $\mathrm{HR}$ recovery, $\mathrm{VE} / \mathrm{VCO}_{2}$ slope) and CVD risk factors (e.g., body weight, resting HR, blood pressure, cholesterol, triglycerides, and fasting glucose) do not appear to be influenced by exercise intensity $(52,82$, 91). Studies investigating 24-hr blood pressure, have found a superior effect of HIIT compared with MICT in patients with hypertension (92) but similar improvement to MICT in patients with HF (93). Pattyn et al. (52) found a trend ( $p$ $=0.09$ ) toward greater improvements in vascular function [via flow-mediated dilation (FMD)] with HIT compared with MICT. In a meta-analysis with a more diverse cohort of cardiometabolic diseases, Ramos et al. (94) found HIIT was superior to MICT with a 2-fold greater improvement in flowmediated dilation ( 4.31 vs. $2.15 \%$, respectively). For changes in body composition, HIIT provides similar benefit compared with MICT, but not when total energy expenditure is less (95). Therefore, exercise volume appears to play a greater role in body composition than exercise intensity (95). A retrospective study by Dun et al. (96) in 120 CR patients with myocardial infarction, found greater reductions in total fat mass and abdominal fat percentage with HIIT compared to MICT using dual-energy x-ray absorptiometry (DEXA). In contrast, Taylor et al. (97) found similar reductions for visceral adipose tissue and subcutaneous fat quantified by magnetic resonance imaging and total fat mass with DEXA, when comparing isocaloric HIIT and MICT in patients with CAD. The influence of exercise intensity on resting left ventricular ejection fraction (LVEF) and left ventricular end-diastolic diameter (LVEDD) remain inconclusive. Meta-analyses by Cornelis et al. (98) and Pattyn et al. (52) both found HIIT significantly improved both LVEF compared with MICT in patients with HF, however Haykowsky et al. (86) found only a trend toward greater improvements in LVEF. Cornelis et al. (98) also found HIIT significantly improved LVEDD compared with MICT. While the multi-center SMARTEX HF study (88) found only HIIT significantly improved LVEDD after 12-weeks compared with the control group, there was no difference between HIIT and MICT.

\section{Influence of Exercise Intensity on Long-Term Outcomes and Adherence}

Only three studies have investigated long-term outcomes of HIIT compared with MICT in patients with CAD at 6-months (85) and 12 -months $(36,99)$. Moholdt et al. (85) found a superior effect of HIIT compared with MICT on improvement of $\mathrm{VO}_{2}$ peak and $\mathrm{HR}$ recovery at 6-months in patients with $\mathrm{CABG}$, but similar improvements in quality of life and adiponectin. At 12-months, the SAINTEX-CAD and FITR Heart studies found similar improvements between HIIT and MICT in patients with CAD for $\mathrm{VO}_{2}$ peak and other exercise variables $(36,99)$, CVD risk factors $(36,99)$, quality of life $(36,99), \operatorname{FMD}(99,100)$, body composition $(97,101)$, moderate-vigorous PA $(36,99)$, and no changes in dietary intake (101). Although for The FITR Heart Study, the improvement in $\mathrm{VO}_{2}$ peak was numerically higher for HIIT $(2.9 \mathrm{~mL} / \mathrm{kg} / \mathrm{min})$ than MICT $(1.8 \mathrm{~mL} / \mathrm{kg} / \mathrm{min})$ (36) which may be related to greater long-term survival as noted above. In contrast, the SMARTEX HF (88) and OptimEX-Clin (89) studies in patients with HFrEF and HFpEF, respectively, showed a regression of supervised training improvements at 12 months regardless of exercise intensity. A difference with The FITR Heart Study (36) and OptimEx-Clin study (89) was after the supervised training period, participants were instructed to continue home-based HIIT or MICT (as randomized) until the 12-month follow-up, and therefore long-term adherence to the HIIT and MICT protocols were assessed. At 12-months, The FITR Heart Study reported $38 \%$ of MICT participants had starting exercising at a higher intensity than prescribed and $24 \%$ of HIT participants exercised at a lower intensity than prescribed, although overall adherence ( $>70 \%$ of sessions at prescribed intensity) was similar between groups ( $53 \%$ for HIIT and $41 \%$ for MICT) (36). When non-adherent participants were excluded from the analysis, HIIT showed a considerably greater improvement in $\mathrm{VO}_{2}$ peak $(5.2 \mathrm{~mL} / \mathrm{kg} / \mathrm{min})$ compared with MICT (2.2 $\mathrm{mL} / \mathrm{kg} / \mathrm{min}$ ) (36), however improvements in other cardiometabolic outcomes remained similar between groups. This demonstrates that adherence to the intensity of exercise protocols over the long-term can significantly influence improvements in $\mathrm{VO}_{2}$ peak. In contrast, Moholdt et al. (85) found after 5 months of home-based training that a higher proportion of participants stopped HIIT in favor of MICT (35\%), compared to only $4 \%$ of MICT participants starting higher intensity exercise. Although adherence to the randomized training ( $\geq 3$ times/week) at 6-months was slightly lower for HIIT (52 \%) than MICT (64\%), the proportion of participants performing 3 sessions/week of at least moderate intensity exercise was similar for HIIT (74\%) and MICT (68\%), and improvements in $\mathrm{VO}_{2}$ peak were superior with HIIT at 6months. In patients with HFpEF, the Optimex-Clin study (89) reported that adherence ( $>70 \%$ of sessions) did not influence improvements in $\mathrm{VO}_{2}$ peak. The authors found similar adherence between HIIT and MICT (56 and $60 \%$, respectively) but did not report on adherence to the intensity of the exercise protocols. A recent review in CR patients with CAD, found short-term adherence (as number of sessions) to supervised or home-based HIIT was similar to MICT (53). However, the review highlighted that adherence to intensity and duration of the training protocols was under-reported, and the authors provided recommendations for how future studies can collect and report this important data (53). This is particularly important given the findings from larger pragmatic trials such as the SAINTEX-CAD, SMARTEX-HF, and FITR Heart studies on nonadherence to training intensity, which can provide insight into feasibility and effectiveness of exercise prescription. The review by Taylor et al. (53) in patients with CAD, found the majority of studies reporting on feasibility (8/11 studies) reported HIIT to be equally feasible to MICT in patients attending CR, while the other three studies reported HIT was less feasible than MICT. Factors that appeared to improve feasibility of HIIT included: setting realistic expectations for training intensities; including a variety of exercise modalities (for enjoyment and reducing musculoskeletal impact); and using progressive models of HIIT (53). 


\section{$\uparrow \mathrm{VO}_{2}$ peak}

\section{[= SV $\times \mathrm{HR} \times\left(\mathrm{a}-\mathrm{VO}_{2}\right.$ difference $\left.)\right]$}
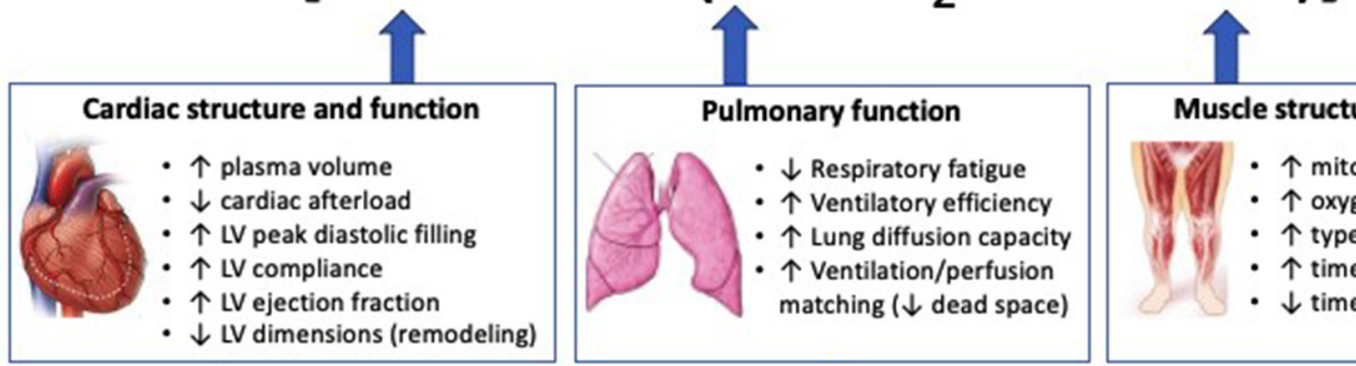

Muscle structure and function

- $\uparrow$ mitochondrial content

- $\uparrow$ oxygen utilization

- $\uparrow$ type 1 aerobic fibers

- $\uparrow$ time for lactate production

- $\downarrow$ time for oxygen extraction
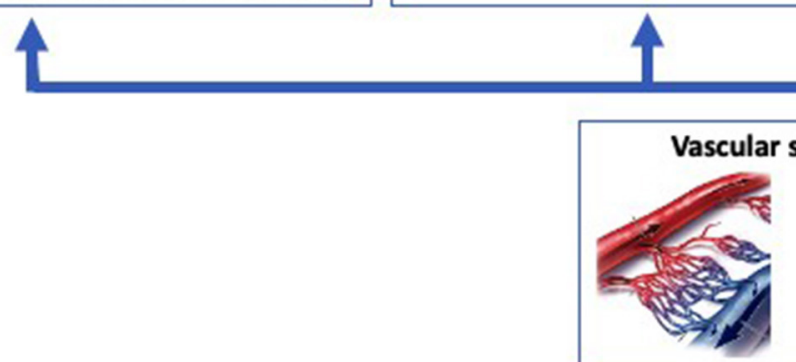

- $\downarrow$ arterial resistance

- $\uparrow$ blood flow distribution

- $\uparrow$ capillarization

FIGURE 1 | Physiological adaptations from exercise training that may contribute to improvement in $\mathrm{VO}_{2}$ peak in patients with cardiovascular disease or heart failure. Cardiac adaptations contribute to $\mathrm{VO}_{2}$ peak improvements primarily through increases in stroke volume. Pulmonary adaptations contribute to $\mathrm{VO}_{2}$ peak by optimizing arterial oxygen content and therefore oxygen delivery. Muscle adaptations contribute to $\mathrm{VO}_{2}$ peak improvements through increased exercise tolerance and enhanced oxygen extraction. Vascular adaptations contribute to oxygen delivery by reducing arterial resistance, increasing capillary density, and enhancing blood flow distribution, which in turn enhances function of the cardiac, pulmonary, and muscle systems. Increases in plasma volume can occur within days of commencing exercise training. Adaptations within skeletal muscle and to the vasculature can occur within weeks of training. Current evidence supports greater adaptations in mitochondrial content, vascular vasodilatory function, and stroke volume following HIIT compared with MICT, although the precise cardiac mechanisms that lead to increased stroke volume remain unclear. $\mathrm{VO}_{2}$ peak, peak oxygen uptake; $\mathrm{SV}$, stroke volume; $\mathrm{HR}$, heart rate; $\mathrm{a}-\mathrm{VO}_{2}$ difference, oxygen content difference between arterial and venous blood; LV, left ventricle.

\section{Physiological Adaptations With Exercise Training for Improving $\mathrm{VO}_{2}$ peak}

There are numerous integrative physiological adaptations that may improve $\mathrm{VO}_{2}$ peak in patients with $\mathrm{CVD}$ or $\mathrm{HF}$ (Figure 1). Based on the Fick equation, $\mathrm{VO}_{2}$ is the product of cardiac output and arterial-venous $\mathrm{O}_{2}$ content difference (a- $\mathrm{vO}_{2}$ difference), where cardiac output is the product of stroke volume and HR (68). This equation can also be summarized as "central" and "peripheral" determinants of $\mathrm{VO}_{2}$, respectively (50).

\section{Pulmonary Adaptations}

The pulmonary system is responsible for the transport of $\mathrm{O}_{2}$ from the atmosphere to the bloodstream, with alveolar ventilation $\left(\mathrm{O}_{2}\right.$ exchange with the atmosphere) and diffusion $\left(\mathrm{O}_{2}\right.$ exchange with the bloodstream) contributing to arterial $\mathrm{O}_{2}$ content, $\mathrm{O}_{2}$ delivery, and $\mathrm{VO}_{2}$ peak (68). Reduced alveolar exchange can be a significant contributor to exercise intolerance in patients with HF, which can occur due to impaired pulmonary vasodilation, ventilation/perfusion mismatch, impaired diffusion, abnormal ventilatory reserve (i.e., respiratory muscle dysfunction), or abnormal ventilatory regulation (i.e., oscillatory patterns) (102-105). Furthermore, respiratory muscle fatigue has also been shown to affect $\mathrm{O}_{2}$ delivery by causing peripheral vasoconstriction and reduced blood flow to skeletal muscles, further exacerbating exercise intolerance (106). There are limited studies comparing the effect of exercise training intensity on pulmonary adaptations. In patients with $\mathrm{HF}$, Tasoulis et al. (107) demonstrated that HIIT improved ventilatory regulation, with an improvement in ventilatory drive (as $\mathrm{P}_{0.1} / \mathrm{PI}_{\max }$ ) and ventilatory patterns during rest and exercise, although there was no control group. In healthy adults, Dunham and Harms (108), demonstrated significant improvements in respiratory muscle function with HIIT and MICT (43 vs. $25 \%$ ) over 4-weeks, however there was a greater increase with HIIT. Finally, Guazzi et al. (109) studied patients with HF, and found that compared with a control group, 8-weeks of moderatevigorous intensity training improved lung diffusion, alveolarcapillary conductance, and pulmonary capillary blood volume with concomitant improvements in $\mathrm{VO}_{2}$ peak. Whether HIIT is superior to MICT for pulmonary adaptations remains unclear.

\section{Cardiac Adaptations}

One of the proposed mechanisms for greater improvement in $\mathrm{VO}_{2}$ peak with higher intensity exercise is greater central 
adaptations in left ventricular structure and function (110), by challenging the cardiac muscle to provide increased cardiac output and $\mathrm{O}_{2}$ to the working muscles (52). In athletes, exercise training is associated with expansion of red blood cell volume and augmented plasma volume (111), reduced total peripheral resistance, and increased LV end-diastolic volumes (i.e., LVEDV), leading to increased stroke volume, cardiac output, and $\mathrm{VO}_{2}$ peak (112). Increased LV diastolic volumes in the shortterm can be attributed to increased plasma volume and venous return via the Frank-Starling mechanism (111), while long-term adaptation involves structural changes from exercise training that enhance LV compliance (112). However, in cardiac patients, who may have pathological LV dilation (cardiomegaly), exercise training has been associated with reversal of LV remodeling (i.e., reduction in LVEDD), increases in peak diastolic filling, and reduced peripheral resistance, with concomitant increases in stroke volume, cardiac output, and $\mathrm{VO}_{2}$ peak $(44,113,114)$. Several studies in healthy subjects $(115,116)$ and patients with $\operatorname{HFrEF}(44,58,117)$ have shown greater improvements in maximal stroke volume alongside $\mathrm{VO}_{2}$ peak with HIIT compared with MICT. In contrast, Iellamo et al. (118) found no improvement in central hemodynamics (cardiac output or stroke volume) for HIIT or MICT in patients with HFrEF despite large increases in $\mathrm{VO}_{2}$ peak for both groups. A proposed reason for differences in central adaptation outcomes between studies, is that some patients with a high degree of peripheral limitation (e.g., muscle atrophy or overt cachexia) may have a limited ability to exercise at a high intensity for a sufficient amount of time (110). Peripheral limitations are known to be a significant contributor to exercise intolerance in patients with HF (102). Inability to achieve the target training intensity of HIIT (51\% participants) was a significant limitation of the SMART-EX HF study in patients with HFrEF (88), which showed no change in LVEDD or peak $\mathrm{O}_{2}$ pulse (a surrogate for stroke volume). In contrast, the SAINTEX-CAD study in patients without HF (84) showed significant improvements in peak $\mathrm{O}_{2}$ pulse for both HIIT and MICT, although the average intensity of the MICT group was $80 \%$ HRpeak and therefore higher than a moderate intensity. In summary, majority of studies investigating central hemodynamics have found greater improvements in stroke volume with HIIT compared with MICT. However, the effect of exercise training intensity on structural adaptations remains unclear.

\section{Vascular Adaptations}

Another potential mechanism for the greater improvement in $\mathrm{VO}_{2}$ peak with higher intensity exercise is the superior effect on vascular function for HIIT compared with MICT $(52,94)$. Greater elasticity and function of the central and peripheral vasculature allows for greater accommodation and more efficient transport of blood and $\mathrm{O}_{2}$ to the heart and skeletal muscles (68). A common method for measuring vascular function adaptations is brachial artery FMD (119), a non-invasive test shown to correlate well with invasively measured coronary artery vasodilatory function (120). There is extensive evidence that aerobic exercise training improves vascular function in large conduit arteries, with repeated hemodynamic stimuli and laminar shear stress playing a central role in vascular adaptation (119). A proposed mechanism for the superior effect of HIIT on vascular function, when compared with MICT, is that higher intensity exercise provokes greater blood flow and shear stress stimulus, that allows for greater vascular adaptation through upregulation of vasodilatory prostaglandins $(119,121)$ and nitric oxide $(119,122)$. Thijssen et al. (123) demonstrated that with incremental increases in exercise intensity for various modalities (walking, cycling, leg kicking), there was a parallel increase in mean blood flow and shear rate within the brachial artery.

\section{Skeletal Muscle Adaptations}

In addition to $\mathrm{O}_{2}$ delivery, peripheral adaptations with training that increase $\mathrm{O}_{2}$ extraction and utilization may also lead to increases in $\mathrm{VO}_{2}$ peak by increasing a- $\mathrm{vO}_{2}$ difference. In healthy populations, skeletal muscle capacity for oxidation usually exceeds the capacity for systemic $\mathrm{O}_{2}$ transport (50), and therefore peripheral adaptations may not contribute to large increases in $\mathrm{VO}_{2}$ peak. However, in deconditioned patients, particularly those with HFrEF and HFpEF, peripheral adaptations within skeletal muscle can have a significant effect on exercise tolerance and capacity $(102,124)$. The major training-induced adaptations that increase $\mathrm{O}_{2}$ extraction and utilization within skeletal muscle, include increased capillary density and mitochondrial volume density (111). The former may enhance local blood perfusion and distribution with or without improvements in vascular function (111), while the latter increases capacity for substrate oxidation at a given workload $(50,125)$. Increased mitochondrial content with exercise training "promotes greater reliance on fat oxidation with a proportional decrease in carbohydrate oxidation," which in turn "reduces glycogen degradation and lactate production at a given workload" $(126,127)$. As a result, lactate threshold is increased and patients can exercise for longer durations at a greater percentage of $\mathrm{VO}_{2}$ peak (128). This is particularly important for cardiac patients, as reduced oxidative capacity can significantly contribute to exercise intolerance (102). There is strong evidence from studies in healthy populations that exercise intensity mediates mitochondrial adaptations to exercise and improvements in $\mathrm{VO}_{2}$ peak (126). During higher intensity exercise, there is greater accumulation of metabolites and free radicals from calcium release, ATP turnover, and carbohydrate utilization $(1,126)$. This accumulation leads to activation of several mitochondrial enzymes, which stimulate expression of peroxisome proliferator-activated receptor $\gamma$ coactivator- $1 a$ (PGC-1a), an important regulator of mitochondrial biogenesis $(50,126)$. Studies involving patients with HF (44), metabolic syndrome (43), and obesity (129) have shown greater increases in PGC-1 $a$ with HIIT compared with MICT, with concomitant increases in the maximal rate of calcium reuptake into the sarcoplasmic reticulum. Enhanced calcium cycling, may also help to reduce muscle fatigue and exercise capacity (51). In addition to exercise intensity, this greater activation of signaling pathways for mitochondrial adaptations is thought to be triggered by the metabolic fluctuations with intermittent exercise bouts, that occurs during interval training (50). In contrast, short bursts of high intensity exercise do not appear to improve vascular endothelial growth factor (VEGF) secretion and skeletal 
muscle capillarization, which may require longer durations of constant work exercise (130). Studies that have found superior improvements in VEGF and skeletal muscle capillarization with MICT compared with HIIT, have used short duration HIIT intervals of $\leq 1 \mathrm{~min}(131,132)$. There is limited research comparing training of different intensities on muscle fiber type. However, studies comparing exercise to a control group, have found an increased proportion of type 1 fibers with decreased type IIb fibers after either 15-weeks of SIT (133) or 6-months of MICT (134). On the other hand, Tan et al. (135), found 6-weeks of HIIT improved oxidative capacity of both type 1 and type 2 muscle fibers to a similar degree. Based on the current evidence, it appears that high intensity exercise provides a potent stimulus for mitochondrial adaptations compared with MICT, however the effect of training intensity on other peripheral adaptations such as capillarization, blood flow distribution, and muscle fiber shift, remain unclear.

\section{Influence of Interval Duration and Protocol Volume on Physiological Adaptations}

Currently, there is no consensus on the optimal HIIT protocol. Moreover, the effectiveness of HIIT protocols may vary according to the physiological adaptation of interest. HIIT protocols have previously been classified by interval duration as short-duration ( $\leq 1 \mathrm{~min})$, medium-duration (1-3 $\mathrm{min})$, or longduration ( $\geq 3 \mathrm{~min})(136,137)$. Furthermore, high-volume HIIT has been defined as protocols that accumulate $\geq 15 \mathrm{~min}$ of high intensity effort per session (138). The Norwegian model (110) involving $4 \times 4 \mathrm{~min}$ high intensity intervals (85-95\%HRpeak) separated by $3 \mathrm{~min}$ active recovery intervals, is an example of a long-duration, high-volume HIIT protocol, that has been studied extensively in populations with CAD and HF. Two meta-analyses in healthy populations suggest that longer interval durations increase $\mathrm{VO}_{2}$ peak to a greater extent than short duration intervals $(139,140)$. This may be related to greater improvements in central adaptations with longer duration intervals. This is supported by Matsuo et al. (116), who compared SIT $(7 \times$ 30 s intervals; $100 \mathrm{kcal})$, HIIT $(3 \times 3$ min intervals; $180 \mathrm{kcal})$ and MICT (40 min; $360 \mathrm{kcal}$ ), and found the greatest increases in stroke volume, $\mathrm{LV}$ mass, and $\mathrm{VO}_{2}$ peak in the HIIT group, followed by the SIT group. Therefore, exercise intensity is important, but also time to reach and maintain an elevated cardiac filling (which can take 1-4 min in athletes) is believed to be necessary for improving maximal cardiac function (41). However, in the meta-analysis by Pattyn et al. in patients with $\mathrm{CAD}$ and $\mathrm{HF}$ (52), subgroup analyses revealed no differences in $\mathrm{VO}_{2}$ peak improvement based on the duration of the HIIT intervals. Instead, intensity of the HIIT intervals appeared more important, with numerically larger increases in $\mathrm{VO}_{2}$ peak with HIIT intervals at a very hard near-maximal effort $(+1.5$ $\mathrm{mL} / \mathrm{kg} / \mathrm{min}$ ) compared with HIIT intervals at a vigorous effort $(+1.1 \mathrm{~mL} / \mathrm{kg} / \mathrm{min})(52)$. Moreover, HIIT protocols with greater total energy expenditure also produced greater gains in $\mathrm{VO}_{2}$ peak (52). This is supported by others, in that high-volume HIIT protocols appear to elicit the greatest increases in $\mathrm{VO}_{2}$ peak $(138,140)$ and vascular function $(94)$.

\section{Practical Application and Progression Models for HIIT in CR Programs Safety Considerations}

While HIIT provides greater improvements in $\mathrm{VO}_{2}$ peak, there remains a concern regarding its safety in cardiac populations (91). A scientific report from the American Heart Association (AHA) (141), outlined that vigorous exercise can acutely and transiently increase risk of sudden cardiac death and acute myocardial infarction in patients with atherosclerotic disease. However, this report and others have highlighted that incidence of these events is greatest in adults who are the least active $(141,142)$. For deconditioned patients, many of their daily living activities can fall into the category of vigorous intensity (143). Concerns around safety should take this into account, as including HIIT with appropriate progression may expose patients to vigorous efforts in a safer and more controlled manner. The most recent systematic review and meta-analysis on safety of HIIT in patients with CVD, found that HIIT showed a low rate of major adverse events for patients with CAD and HF when applied in CR settings (144). As all studies within the review had included baseline exercise testing, this was a recommendation from the authors prior to HIIT (144). However, maximal exercise testing is not routinely conducted in many CR settings, although guidelines in North America and Europe do recommend electrocardiographic exercise testing as standard procedure (14). The FITR Heart Study medically excluded $3 \%$ of participants following baseline exercise testing, however the need for further coronary intervention was very low (1\%) (36). The AHA report (141), also outlines that appropriate screening and exclusion of high-risk patients from vigorous activities, can help to minimize the incidence of $\mathrm{CV}$ events. To assist clinicians in safely implementing HIIT without maximal exercise testing, guidelines have been published on screening and monitoring for HIIT in clinical populations (26). For example, three studies have reported a hypotensive event during HIIT $(36,88,145)$. Therefore, in patients taking anti-hypertensive medication, a gradual and extended cooldown is recommended, particularly if medications have been recently modified (26). Given the higher risk of CV events with vigorous activity in adults who are less physically fit and active (141, 142), starting patients with a lead-in period of MICT is a sensible approach to ensure proper education on exercise training, assess exercise response, improve exercise tolerance, and minimize musculoskeletal injuries, particularly for patients who are unaccustomed to vigorous exercise (144). Furthermore, progressively increasing interval duration and time spent at a vigorous intensity (see practical applications section), may improve safety and exercise tolerance. Recent guidelines from the European Society of Cardiology (146) outline that high intensity exercise is appropriate for low risk revascularized patients with $\mathrm{CAD}$, if they are asymptomatic and stable, and without residual high risk CAD lesions or exercise-induced arrhythmias. For patients with HF (reduced and preserved ejection fraction), high intensity exercise can also be prescribed for patients who are stable and without exercise-induced arrhythmias (146). Further studies are required to determine whether high intensity exercise is safe in higher risk patients with CAD or HF. 


\section{Intensity Prescription of HIIT}

As outlined earlier in this review, all methods of exercise prescription have their advantages and limitations in patients with CVD and HF. For this reason, we recommend using both objective and subjective measures to prescribe exercise intensity for HIIT. The multicenter SAINTEX-CAD study relied only on objective measures of intensity for HIIT prescription, and subsequently found and acknowledged that when prescribing HIIT "it is necessary to adjust the objectively defined target HR zones and workloads according to the patient's subjective feelings." Furthermore, the SAINTEX-CAD study (84) and Pattyn et al. (52) have found significant increases in HRpeak over 12 -weeks of training. This suggests that target HR zones may need to be adapted over the training period, either by repeating a maximal exercise test, or using subjective measures of intensity to titrate the workload accordingly. Patients may experience the same external training load (e.g., \%HRpeak) differently depending on their individual "internal" metabolic responses to changes in exercise intensity (e.g., lactate accumulation) (147). Therefore, subjective measures are important to consider, and RPE has been shown to be a good indicator of internal training load (37). Currently the most common methods for prescribing HIIT that are also practical for clinical settings, are \%HRpeak and RPE. For shorter duration intervals ( $<2 \mathrm{~min}$ ), \%HRpeak may underestimate the training stimulus due to insufficient time for $\mathrm{HR}$ to rise and $\mathrm{HR}$ lag compared with $\mathrm{VO}_{2}$ response $(41,53)$, particularly in patients with HF or chronotropic incompetence. For long-duration HIIT, a framework for clinicians on using a combination of \%HRpeak and RPE for HIIT prescription has previously been outlined by Taylor et al. (26). This framework involves using a maximally-derived or estimated HRpeak to determine a training target of 85-95\%HRpeak, in combination with a validation session with RPE of 15-18 by the patient, or observer (clinician supervising the exercise) if a patient has difficulty reporting an accurate RPE. Although it is practically attractive for clinicians to solely use RPE for HIIT prescription, Aamot et al. (148) found that using an RPE of 17 (very hard) alone for HIIT prescription, results in a lower mean training intensity (82 \%HRpeak) than a target range of 85-95\%HRpeak. Therefore, HR monitoring in combination with RPE during HIIT may result in greater adherence to exercise intensity targets that are optimal for HIIT (85-95 \%HRpeak).

\section{Incorporating HIIT Into the Optimal Exercise Dose}

Exercise volume, or "dose" encompasses both exercise intensity and duration of exercise (21). According to current PA guidelines from the World Health Organization (149) and US Department of Health (150), it is recommended that adults (even those with chronic health conditions) should accumulate 150-300 $\mathrm{min} /$ week of moderate intensity exercise, or 75-150 min/week of vigorous intensity exercise, or an equivalent combination of moderate and vigorous exercise. In the context of highvolume HIIT protocols that typically involve $\sim 16 \mathrm{~min} / \mathrm{session}$ of high intensity effort and 10-15 min/session of moderate intensity effort, three sessions/week of high-volume HIIT would provide $\sim 48 \mathrm{~min} /$ week of vigorous exercise and $\sim 45 \mathrm{~min} /$ week of moderate exercise. While this may approach the minimum level of the PA recommendations, guidelines advocate for achieving more than the minimum level of PA to sustain optimal health $(149,150)$. Moreover, it is recommended that patients undergoing $\mathrm{CR}$, progress to an optimal weekly exercise dose equivalent to $1,500 \mathrm{kcal} /$ week $(151,152)$. For example, a highvolume HIIT protocol in patients with CAD measured energy expenditure to be $\sim 50 \mathrm{~L} \mathrm{O}_{2} /$ session (42) [equating to $\sim 250$ $\mathrm{kcal} / \mathrm{session}$ with ACSM estimation of $1 \mathrm{~L} \mathrm{VO} 2=5 \mathrm{kcal}(21)]$. Therefore, three sessions/week would equate to half the weekly exercise dose that patients undergoing CR should progress to $(1,500 \mathrm{kcal} /$ week $)(151,152)$. To extend the volume of training beyond the minimum level of PA recommendations and progress to $1,500 \mathrm{kcal} /$ week, while also allowing for variety of exercise training, HIIT can be prescribed as an adjunct rather than alternative to MICT. For example, HIIT could be prescribed as 3 sessions/week in combination with 2-3 sessions/week of MICT and/or resistance training. Alternating days of HIIT and MICT training may also aid in recovery from HIIT sessions while reducing the potential for musculoskeletal discomfort.

Exercise volume can also be quantified as MET-min per week, which is calculated as intensity (in METs) multiplied by the number of minutes at that intensity, accumulated over a week. Current PA guidelines recommend 500-1,000 MET-min per week from moderate-vigorous activities (153). According to ACSM (49), average METs for moderate intensity exercise ranges from 3.0 to 5.9 METs, vigorous intensity exercise ranges from 6.0 to $8.7 \mathrm{METs}$, and near-maximal intensity exercise is $\geq 8.8 \mathrm{METs}$, although these MET ranges can vary according to age. For use in clinical practice, METs can be estimated from treadmill and cycle workload equations $(21,154,155)$, a list of PA intensities (156), and/or some commercial exercise equipment can provide an estimate of METs.

In addition to energy expenditure, methods have been explored that consider individual "internal" training responses to quantify and monitor training dose (147). For example, the training impulse (TRIMP) is calculated by multiplication of (1) the duration of a specific training session, (2) the average change in HR (i.e., HRexercise-HRrest/HRmax-HRrest) during the training session, and (3) an individual weighting factor to reflect metabolic effort (157). This weighting factor is calculated from a maximal exercise test as the best-fitting exponential line from a plot of blood lactate concentration against fractional elevation in HR (157). Given the potential complexities of this method in a clinical setting (i.e., availability of maximal exercise testing, blood lactate measurement, and limitations with HRmax), a sessionRPE method (i.e., RPE representative of the overall session multiplied by session duration), has been validated in patients with $\mathrm{HF}$ as an alternative to TRIMP for monitoring training dose (37). However, further research is needed to determine the optimal weekly session-RPE for CR programs.

\section{Interval Duration and Progression of HIIT}

Although high-volume HIIT with longer-duration intervals may increase exercise dose and provide superior improvements in central adaptations, vascular adaptations, and $\mathrm{VO}_{2}$ peak, sustaining high intensity of exercise for longer than 1-2 min may be challenging for some patients commencing a CR program. In particular, patients who are exercise naïve (137) and/or have a high degree of exercise intolerance (from skeletal muscle 
dysfunction, respiratory limitations, reduced cardiac reserve, or a combination of these factors) (102), would benefit from a more gradual introduction to HIIT. Primary components of exercise prescription defined by ACSM include frequency, intensity, time, type, volume, and progression (FITT-VP) (21). Progression can often be a difficult component of exercise prescription for clinicians to master, but essential to optimize gains in $\mathrm{VO}_{2}$ peak and minimize adverse complications (151). In athletic and healthy populations progression has traditionally involved the training principles of progressive overload, specificity, and periodization (136). It seems appropriate that throughout a CR program, patients may undergo progression from short-duration intervals, to medium-duration intervals, and finally to longduration intervals as training-induced physiological adaptations occur and exercise tolerance improves $(137,158)$. Overload is defined as "an exercise dose which is above and beyond the accustomed amount of exercise for a given individual" (151). For aerobic training, it is generally recommended to just increase one

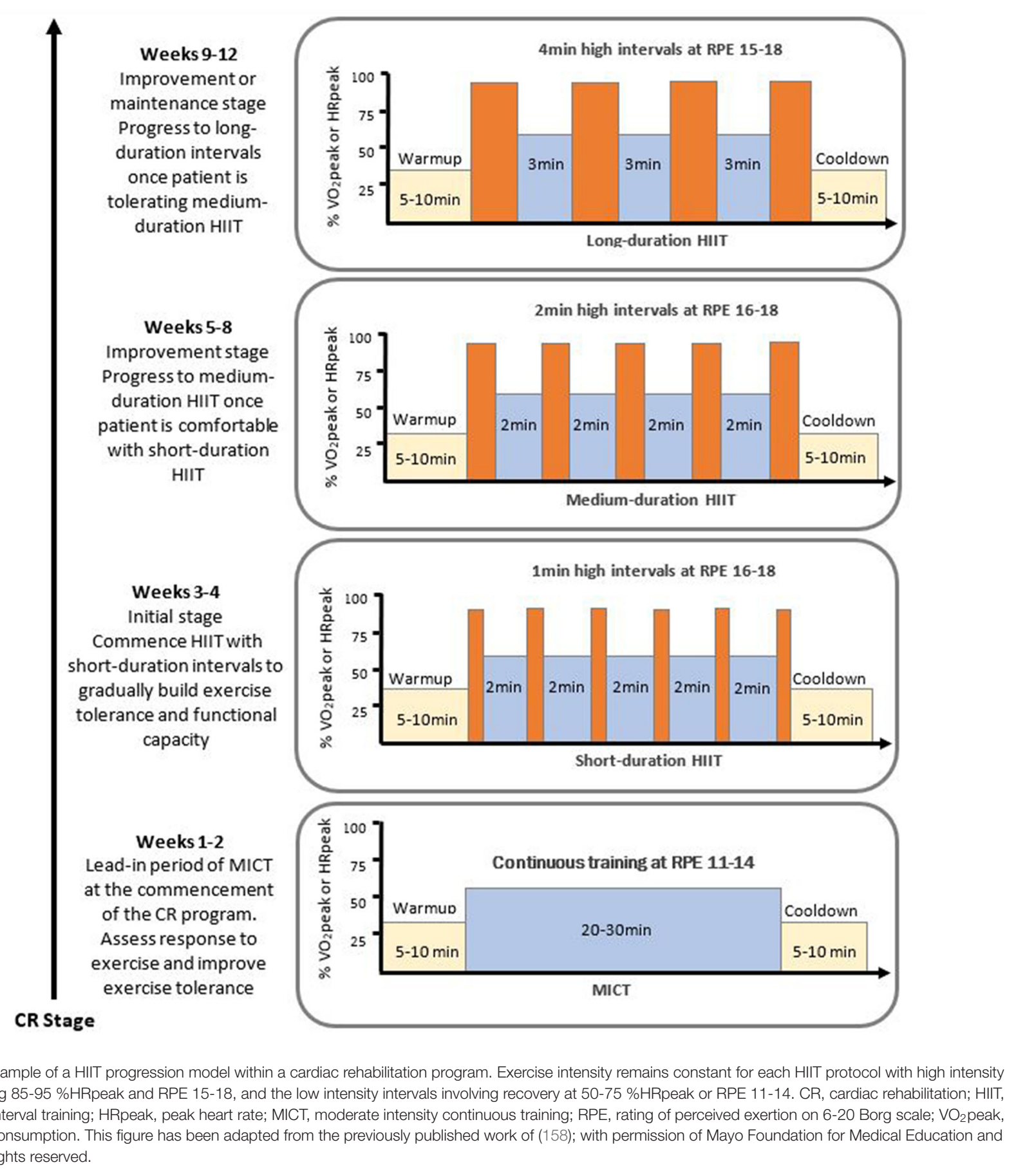


component of frequency, intensity, or duration at a time (151). As suggested by Wewege et al. (144), commencing a CR program with a "lead-in period" of MICT seems appropriate before commencing HIIT. This may allow for a graduated approach to evaluate a patient's exercise response, improve exercise tolerance, and aid in minimizing adverse events and musculoskeletal injuries (144). Furthermore, in terms of progression, it is generally recommended in cardiac patients that "duration and frequency of exercise should be up-titrated before intensity is increased" (to $\geq 30 \mathrm{~min} / \mathrm{session}, 4$ days/week) $(159,160)$. Once patients are tolerating $30 \mathrm{~min}$ of MICT, intensity could then be progressed to include short-duration HIIT, which may provide a greater stimulus than MICT for improving mitochondrial volume and oxidative capacity (50). Adaptations to mitochondrial content have been shown to occur at a rapid rate, with as little as 6 sessions of HIIT in healthy populations (126). Further progressions in interval duration from mediumduration to long-duration could then be made throughout the CR program, to further improvements in central adaptations (116), vascular function (94), and $\mathrm{VO}_{2}$ peak $(138,140)$. Another option for progression is to introduce HIIT once/week initially and then progress to 2-3 sessions/week.

\section{HIIT Progression Model Example}

In Figure 2 we provide an example of how HIIT commencement and progression could occur during a CR program. Following a 2-week lead-in period of MICT, patients with low functional capacity $[<5$ metabolic equivalent (METs)] (161) or in the initial stage of HIIT, can commence a short-duration HIIT protocol (e.g., $1 \mathrm{~min}$ HIIT interval every 3-4 min of MICT), with progression to reduce the recovery interval timing to $2 \mathrm{~min}$. As patients understanding of exercise training and comfort level with the available training modalities increases to an acceptable level, further progressions in interval duration to mediumduration intervals could be prescribed (e.g., 2-3 min HIIT with $2 \mathrm{~min}$ recovery). Initially, clinicians may want to keep the total time at high intensity constant (e.g., from $6 \times 1 \mathrm{~min}$ HIIT to $3 \times 2 \mathrm{~min}$ HIIT), and then gradually progress the number of intervals to $5 \times 2 \mathrm{~min}$ or $4 \times 3 \mathrm{~min}$ over a number of weeks by just changing one prescription factor (interval frequency or duration) at a time. Once patients are comfortable with $4 \times 3 \mathrm{~min}$

\section{REFERENCES}

1. Hansen D, Abreu A, Ambrosetti M, Cornelissen V, Gevaert A, Kemps $\mathrm{H}$, et al. Exercise intensity assessment and prescription in cardiovascular rehabilitation and beyond: why and how: a position statement from the secondary prevention and rehabilitation section of the european association of preventive cardiology. Eur J Prev Cardiol. (2021). 2:zwab007. doi: 10.1093/eurjpc/zwab007

2. Rauch B, Davos CH, Doherty P, Saure D, Metzendorf M-I, Salzwedel A, et al. The prognostic effect of cardiac rehabilitation in the era of acute revascularisation and statin therapy: a systematic review and meta-analysis of randomized and non-randomized studies - The Cardiac Rehabilitation Outcome Study (CROS). Eur J Prev Cardiol. (2016) 23:191439. doi: 10.1177/2047487316671181

3. Salzwedel A, Jensen K, Rauch B, Doherty P, Metzendorf MI, Hackbusch M, et al. Effectiveness of comprehensive cardiac rehabilitation in coronary artery intervals, patients could be progressed to 4-min intervals with $3 \mathrm{~min}$ recovery for a high-volume HIIT protocol (e.g., $4 \times 4 \mathrm{~min}$ ) to further improvements in central adaptations (116), vascular function (94), and $\mathrm{VO}_{2}$ peak $(138,140)$. Once again, clinicians may want to initially keep the total time at high intensity constant (e.g., from $4 \times 3 \mathrm{~min}$ HIIT to $3 \times 4 \mathrm{~min}$ HIIT) and then progress the number of intervals to $4 \times 4 \mathrm{~min}$ HIIT.

\section{CONCLUSION}

There is extensive evidence that higher intensity exercise contributes to greater improvements in $\mathrm{VO}_{2}$ peak than MICT or low intensity exercise, by increments that are known to be clinically meaningful. Higher intensity exercise also produces greater improvements in $\mathrm{VO}_{2}$ at submaximal exercise, which is important for exercise tolerance and carrying out daily living activities. While short-duration HIIT protocols can be a potent stimulus for improving peripheral mitochondrial adaptations and providing similar $\mathrm{VO}_{2}$ peak improvements to MICT, longer-duration and higher-volume HIIT protocols seem to be superior for eliciting stroke volume and vascular adaptations, and greater $\mathrm{VO}_{2}$ peak improvements compared with MICT. Finally, rather than adopting a one-size fits all model for HIIT, gradual introduction and progression of HIT in accordance with individual exercise experience and tolerance, may be optimal for reducing musculoskeletal discomfort, as well as maximizing safety, adherence, enjoyment, and physiological outcomes.

\section{AUTHOR CONTRIBUTIONS}

JLT, ARB, and TPO all contributed to the conception of the manuscript idea and design. JLT was responsible for composing the manuscript. ARB and TPO provided critical revision of the manuscript. All authors contributed to the article and approved the submitted version.

\section{FUNDING}

Open access fees were funded by Department of Cardiovascular Medicine, Mayo Clinic. disease patients treated according to contemporary evidence based medicine: update of the cardiac rehabilitation outcome study (CROS-II). Eur J Prev Cardiol. (2020) 27:1756-74. doi: 10.1177/2047487320905719

4. Heran BS, Chen JM, Ebrahim S, Moxham T, Oldridge N, Rees K, et al. Exercise-based cardiac rehabilitation for coronary heart disease. Cochrane Database Syst Rev. (2011). 6:CD001800. doi: 10.1002/14651858.CD001800.pub2

5. Taylor RS, Brown A, Ebrahim S, Jolliffe J, Noorani H, Rees K, et al. Exercisebased rehabilitation for patients with coronary heart disease: systematic review and meta-analysis of randomized controlled trials. Am J Med. (2004) 116:682-92. doi: 10.1016/j.amjmed.2004.01.009

6. Long L, Mordi IR, Bridges C, Sagar VA, Davies EJ, Coats AJ, et al. Exercisebased cardiac rehabilitation for adults with heart failure. Cochrane Database Syst Rev. (2019) 1:Cd003331. doi: 10.1002/14651858.CD003331.pub5

7. West RR, Jones DA, Henderson AH. Rehabilitation after myocardial infarction trial (RAMIT): multi-centre randomised controlled trial of 
comprehensive cardiac rehabilitation in patients following acute myocardial infarction. Heart. (2012) 98:637-44. doi: 10.1136/heartjnl-2011-300302

8. Anderson L, Oldridge N, Thompson DR, Zwisler A-D, Rees K, Martin $\mathrm{N}$, et al. Exercise-based cardiac rehabilitation for coronary heart disease: cochrane systematic review and meta-analysis. J Am Coll Cardiol. (2016) 67:1-12. doi: 10.1016/j.jacc.2015.10.044

9. Powell R, McGregor G, Ennis S, Kimani PK, Underwood M. Is exercisebased cardiac rehabilitation effective? A systematic review and metaanalysis to re-examine the evidence. BMJ Open. (2018) 8:e019656. doi: 10.1136/bmjopen-2017-019656

10. Conraads VM, Denollet J, De Maeyer C, Van Craenenbroeck E, Verheyen J, Beckers P. Exercise training as an essential component of cardiac rehabilitation. Heart. (2012) 98:674. doi: 10.1136/heartjnl-2012-301912

11. Franklin BA. Multifactorial cardiac rehabilitation did not reduce mortality or morbidity after acute myocardial infarction. Ann. Internal Med. (2012) 157:JC1-11. doi: 10.7326/0003-4819-157-2-201207170-02011

12. Ingle L, Carroll S. Cardiac rehabilitation and exercise training. Heart. (2013) 99:1298. doi: 10.1136/heartjnl-2013-304015

13. Nichols S, Taylor C, Goodman T, Page R, Kallvikbacka-Bennett A, Nation $\mathrm{F}$, et al. Routine exercise-based cardiac rehabilitation does not increase aerobic fitness: a CARE CR study. Int J Cardiol. (2020) 305:25-34. doi: 10.1016/j.ijcard.2020.01.044

14. Price KJ, Gordon BA, Bird SR, Benson AC. A review of guidelines for cardiac rehabilitation exercise programmes: is there an international consensus? Eur J Prev Cardiol. (2016) 23:1715-33.

15. Vromen T, Spee RF, Kraal JJ, Peek N, van Engen-Verheul MM, Kraaijenhagen RA, et al. Exercise training programs in Dutch cardiac rehabilitation centres. Neth Heart J. (2013) 21:138-43. doi: 10.1007/s12471-013-0374-2

16. Korenfeld Y, Mendoza-Bastidas C, Saavedra L, Montero-Gómez A, PerezTerzic C, Thomas RJ, et al. Current status of cardiac rehabilitation in Latin America and the Caribbean. Am Heart J. (2009) 158:480-7. doi: 10.1016/j.ahj.2009.06.020

17. Hannan AL, Hing W, Climstein M, Coombes JS, Furness J, Jayasinghe R, et al. Australian cardiac rehabilitation exercise parameter characteristics and perceptions of high-intensity interval training: a cross-sectional survey. Open Access J Sports Med. (2018) 9:79-89. doi: 10.2147/OAJSM.S160306

18. Borghi-Silva A, Mendes RG, Trimer R, Cipriano G. Current trends in reducing cardiovascular disease risk factors from around the world: focus on cardiac rehabilitation in Brazil. Prog Cardiovasc Dis. (2014) 56:536-42. doi: 10.1016/j.pcad.2013.09.008

19. Borg GA. Psychophysical bases of perceived exertion. Med Sci Sports Exerc. (1982) 14:377-81.

20. Reed JL, Pipe AL. The talk test: a useful tool for prescribing and monitoring exercise intensity. Curr Opin Cardiol. (2014) 29:475-80. doi: 10.1097/HCO.0000000000000097

21. American College of Sports Medicine. ACSM's Guidelines for Exercise Testing and Prescription, 10th Edn. Philadelphia, PA: Lippincott Williams \& Wilkins (2018).

22. Carvalho VO, Mezzani A. Aerobic exercise training intensity in patients with chronic heart failure: principles of assessment and prescription. Eur J Cardiovasc Prev Rehabil. (2011) 18:5-14. doi: 10.1097/HJR.0b013e32833a9c63

23. Casillas J-M, Gudjoncik A, Gremeaux V, Aulagne J, Besson D, Laroche D. Assessment tools for personalizing training intensity during cardiac rehabilitation: Literature review and practical proposals. Ann Phys Rehabil Med. (2017) 60:43-9. doi: 10.1016/j.rehab.2016.01.011

24. Reed JL, Pipe AL. Practical approaches to prescribing physical activity and monitoring exercise intensity. Can J Cardiol. (2016) 32:514-22. doi: 10.1016/j.cjca.2015.12.024

25. Reeves RG, Gupta ES, Forman ED. Evolving role of exercise testing in contemporary cardiac rehabilitation. J Cardiopulm Rehabil Prev. (2016) 36:309-19. doi: 10.1097/HCR.0000000000000176

26. Taylor JL, Holland DJ, Spathis JG, Beetham KS, Wisløff U, Keating SE, et al. Guidelines for the delivery and monitoring of high intensity interval training in clinical populations. Prog Cardiovasc Dis. (2019) 62:140-6. doi: 10.1016/j.pcad.2019.01.004

27. Balady Gary J, Arena R, Sietsema K, Myers J, Coke L, Fletcher Gerald F, et al. Clinician's guide to cardiopulmonary exercise testing in adults. Circulation. (2010) 122:191-225. doi: 10.1161/CIR.0b013e3181e $52 \mathrm{e} 69$

28. Mezzani A, Hamm LF, Jones AM, McBride PE, Moholdt T, Stone JA, et al. Aerobic exercise intensity assessment and prescription in cardiac rehabilitation: a joint position statement of the European Association for Cardiovascular Prevention and Rehabilitation, the American Association of Cardiovascular and Pulmonary Rehabilitation and the Canadian Association of Cardiac Rehabilitation. Eur J Prev Cardiol. (2013) 20:442-67. doi: 10.1177/2047487312460484

29. Bensimhon DR, Leifer ES, Ellis SJ, Fleg JL, Keteyian SJ, Piña IL, et al. Reproducibility of peak oxygen uptake and other cardiopulmonary exercise testing parameters in patients with heart failure (from the Heart Failure and A Controlled Trial Investigating Outcomes of exercise traiNing). Am J Cardiol. (2008) 102:712-7. doi: 10.1016/j.amjcard.2008.04.047

30. Myers J, Goldsmith RL, Keteyian SJ, Brawner CA, Brazil DA, Aldred H, et al. The ventilatory anaerobic threshold in heart failure: a multicenter evaluation of reliability. J Card Fail. (2010) 16:76-83. doi: 10.1016/j.cardfail.2009.08.009

31. Whipp BJ. Dynamics of pulmonary gas exchange. Circulation. (1987) 76(6 Pt 2):Vi18-28.

32. Chatterjee NA, Murphy RM, Malhotra R, Dhakal BP, Baggish $\mathrm{AL}$, Pappagianopoulos PP, et al. Prolonged mean $\mathrm{VO}_{2}$ response time in systolic heart failure. Circ Heart Fail. (2013) 6:499-507. doi: 10.1161/CIRCHEARTFAILURE.112.000157

33. Hearon Jr CM, Sarma S, Dias KA, Hieda M, Levine BD. Impaired oxygen uptake kinetics in heart failure with preserved ejection fraction. Heart. (2019) 105:1552. doi: 10.1136/heartjnl-2019-314797

34. Koike A, Yajima T, Adachi H, Shimizu N, Kano H, Sugimoto K, et al. Evaluation of exercise capacity using submaximal exercise at a constant work rate in patients with cardiovascular disease. Circulation. (1995) 91:1719-24. doi: 10.1161/01.CIR.91.6.1719

35. Ilarraza $H$, Myers J, Kottman W, Rickli H, Dubach P. An evaluation of training responses using self-regulation in a residential rehabilitation program. J Cardiopulm Rehabil. (2004) 24:27-33. doi: 10.1097/00008483-200401000-00006

36. Taylor JL, Holland DJ, Keating SE, Leveritt MD, Gomersall SR, Rowlands AV, et al. Short-term and long-term feasibility, safety, and efficacy of high-intensity interval training in cardiac rehabilitation: the FITR heart study randomized controlled trial. JAMA Cardiol. (2020) 5:1-9. doi: 10.1001/jamacardio.2020.3511

37. Iellamo F, Manzi V, Caminiti G, Vitale C, Massaro M, Cerrito A, et al. Validation of rate of perceived exertion-based exercise training in patients with heart failure: insights from autonomic nervous system adaptations. Int J Cardiol. (2014) 176:394-8. doi: 10.1016/j.ijcard.2014.07.076

38. Levinger I, Bronks R, Cody DV, Linton I, Davie A. Perceived exertion as an exercise intensity indicator in chronic heart failure patients on Beta-blockers. J Sports Sci Med. (2004) 3(YISI 1):23-27.

39. Buckley JP, Sim J, Eston RG. Reproducibility of ratings of perceived exertion soon after myocardial infarction: responses in the stress-testing clinic and the rehabilitation gymnasium. Ergonomics. (2009) 52:421-7. doi: 10.1080/00140130802707691

40. Gondoni LA, Nibbio F, Caetani G, Augello G, Titon AM. What are we measuring? Considerations on subjective ratings of perceived exertion in obese patients for exercise prescription in cardiac rehabilitation programs. Int J Cardiol. (2010) 140:236-8. doi: 10.1016/j.ijcard.2008.11.068

41. Buchheit M, Laursen PB. High-intensity interval training, solutions to the programming puzzle: Part I: cardiopulmonary emphasis. Sports medicine (Auckland, NZ). (2013) 43:313-38. doi: 10.1007/s40279-013-0029-x

42. Rognmo O, Hetland E, Helgerud J, Hoff J, Slordahl SA. High intensity aerobic interval exercise is superior to moderate intensity exercise for increasing aerobic capacity in patients with coronary artery disease. Eur J Cardiovasc Prev Rehabil. (2004) 11:216-22. doi: 10.1097/01.hjr.0000131677.96762.0c

43. Tjønna AE, Lee SJ, Rognmo $\varnothing$, Stølen TO, Bye A, Haram PM, et al. Aerobic interval training versus continuous moderate exercise as a treatment for the metabolic syndrome: a pilot study. Circulation. (2008) 118:346-54. doi: 10.1161/CIRCULATIONAHA.108.772822

44. Wisløff U, Støylen A, Loennechen JP, Bruvold M, Rognmo $\varnothing$, Haram PM, et al. Superior cardiovascular effect of aerobic interval training versus moderate continuous training in heart failure 
patients: a randomized study. Circulation. (2007) 115:3086-94. doi: 10.1161/CIRCULATIONAHA.106.675041

45. Casillas JM, Joussain C, Gremeaux V, Hannequin A, Rapin A, Laurent Y, et al. A study of the 200-metre fast walk test as a possible new assessment tool to predict maximal heart rate and define target heart rate for exercise training of coronary heart disease patients. Clin Rehabil. (2015) 29:175-83. doi: $10.1177 / 0269215514540922$

46. Keteyian SJ, Kitzman D, Zannad F, Landzberg J, Arnold JM, Brubaker P, et al. Predicting maximal HR in heart failure patients on $\beta$-blockade therapy. Med Sci Sports Exerc. (2012) 44:371-76. doi: 10.1249/MSS.0b013e318234316f

47. Nes BM, Janszky I, Wisloff U, Stoylen A, Karlsen T. Age-predicted maximal heart rate in healthy subjects: the HUNT fitness study. Scand J Med Sci Sports. (2013) 23:697-704. doi: 10.1111/j.1600-0838.2012.01445.x

48. Tanaka H, Monahan KD, Seals DR. Age-predicted maximal heart rate revisited. J Am Coll Cardiol. (2001) 37:153-6. doi: 10.1016/S0735-1097(00)01054-8

49. Garber CE, Blissmer B, Deschenes MR, Franklin BA, Lamonte MJ, Lee IM, et al. American College of Sports Medicine position stand. Quantity and quality of exercise for developing and maintaining cardiorespiratory, musculoskeletal, and neuromotor fitness in apparently healthy adults: guidance for prescribing exercise. Med Sci Sports Exerc. (2011) 43:1334-59. doi: 10.1249/MSS.0b013e318213fefb

50. Gibala MJ. Physiological basis of interval training for performance enhancement. Exp Physiol. (2020) 1-4. doi: 10.1113/ep088190

51. Weston KS, Wisløff U, Coombes JS. High-intensity interval training in patients with lifestyle-induced cardiometabolic disease: a systematic review and meta-analysis. Br J Sports Med. (2014) 48:1227. doi: 10.1136/bjsports-2013-092576

52. Pattyn N, Beulque R, Cornelissen V. Aerobic Interval vs. Continuous training in patients with coronary artery disease or heart failure: an updated systematic review and meta-analysis with a focus on secondary outcomes. Sports Med. (2018) 48:1189-205. doi: 10.1007/s40279-018-0885-5

53. Taylor JL, Holland DJ, Keating SE, Bonikowske AR, Coombes JS. Adherence to high-intensity interval training in cardiac rehabilitation: a REVIEW AND RECOMMENDATIONS. J Cardiopulm Rehabil Prev. (2021) 41:61-77. doi: 10.1097/HCR.0000000000000565

54. Lee LS, Tsai M-C, Brooks D, Oh PI. Randomised controlled trial in women with coronary artery disease investigating the effects of aerobic interval training versus moderate intensity continuous exercise in cardiac rehabilitation: CAT versus MICE study. BMJ Open Sport Exerc Med. (2019) 5:e000589. doi: 10.1136/bmjsem-2019-000589

55. Lee LS, Tsai M-C, Oh PI, Brooks D. The Effectiveness of Progressive Aerobic Interval Training in Cardiac Rehabilitation. Med Sci Sports Exerc. (2018) 50:881-8. doi: 10.1249/MSS.0000000000001526

56. Tschentscher M, Eichinger J, Egger A, Droese S, Schonfelder M, Niebauer J. High-intensity interval training is not superior to other forms of endurance training during cardiac rehabilitation. Eur J Prev Cardiol. (2016) 23:14-20. doi: 10.1177/2047487314560100

57. Jaureguizar KV, Vicente-Campos D, Bautista LR, de la Pena CH, Gomez MJ, Rueda MJ, et al. Effect of high-intensity interval versus continuous exercise training on functional capacity and quality of life in patients with coronary artery disease: a RANDOMIZED CLINICAL TRIAL. J Cardiopulm Rehabil Prev. (2016) 36:96-105. doi: 10.1097/HCR.0000000000000156

58. Freyssin C, Verkindt C, Prieur F, Benaich P, Maunier S, Blanc P. Cardiac rehabilitation in chronic heart failure: effect of an 8 -week, high-intensity interval training versus continuous training. Arch Phys Med Rehabil. (2012) 93:1359-64. doi: 10.1016/j.apmr.2012.03.007

59. Aksoy S, Findikoglu G, Ardic F, Rota S, Dursunoglu D. Effect of 10week supervised moderate-intensity intermittent vs. Continuous aerobic exercise programs on vascular adhesion molecules in patients with heart failure. Am J Phys Med Rehabil. (2015) 94(10 Suppl. 1):898-911. doi: 10.1097/PHM.0000000000000306

60. Wisløff U, Nilsen TI, Drøyvold WB, Mørkved S, Slørdahl SA, Vatten LJ. A single weekly bout of exercise may reduce cardiovascular mortality: how little pain for cardiac gain? 'The HUNT study, Norway'. Eur J Cardiovasc Prev Rehabil. (2006). 13:798-804. doi: 10.1097/01.hjr.0000216548.84560.ac

61. Wen CP, Wai JP, Tsai MK, Yang YC, Cheng TY, Lee MC, et al. Minimum amount of physical activity for reduced mortality and extended life expectancy: a prospective cohort study. Lancet. (2011) 378:1244-53. doi: 10.1016/S0140-6736(11)60749-6

62. Gebel K, Ding D, Chey T, Stamatakis E, Brown WJ, Bauman AE. Effect of moderate to vigorous physical activity on all-cause mortality in middle-aged and older australians. JAMA Intern Med. (2015) 175:970-7. doi: 10.1001/jamainternmed.2015.0541

63. Wang Y, Nie J, Ferrari G, Rey-Lopez JP, Rezende LFM. Association of physical activity intensity with mortality: a national cohort study of 403681 US adults. JAMA Internal Med. (2021) 181:203-11. doi: 10.1001/jamainternmed.2020.6331

64. Tanasescu M, Leitzmann MF, Rimm EB, Willett WC, Stampfer MJ, Hu FB. Exercise type and intensity in relation to coronary heart disease in men. JAMA. (2002) 288:1994-2000. doi: 10.1001/jama.288.16.1994

65. Lee IM, Sesso HD, Oguma Y, Paffenbarger RS, Jr. Relative intensity of physical activity and risk of coronary heart disease. Circulation. (2003). 107:1110-6. doi: 10.1161/01.cir.0000052626.63602.58

66. Manson JE, Hu FB, Rich-Edwards JW, Colditz GA, Stampfer MJ, Willett WC, et al. A prospective study of walking as compared with vigorous exercise in the prevention of coronary heart disease in women. $N$ Engl J Med. (1999) 341:650-8. doi: 10.1056/NEJM199908263410904

67. Lee IM, Rexrode KM, Cook NR, Manson JE, Buring JE. Physical activity and coronary heart disease in womenis "no pain, no gain" passé? JAMA. (2001) 285:1447-54. doi: 10.1001/jama.285.11.1447

68. Ross R, Blair SN, Arena R, Church TS, Despres JP, Franklin BA, et al. Importance of assessing cardiorespiratory fitness in clinical practice: a case for fitness as a clinical vital sign: a scientific statement from the american heart association. Circulation. (2016) 134:e653-99. doi: 10.1161/CIR.0000000000000461

69. Mikkelsen N, Cadarso-Suarez C, Lado-Baleato O, Diaz-Louzao $\mathrm{C}$, Gil CP, Reeh J, et al. Improvement in $\mathrm{VO}_{2}$ peak predicts readmissions for cardiovascular disease and mortality in patients undergoing cardiac rehabilitation. Eur J Prev Cardiol. (2020) 27:811-9. doi: 10.1177/2047487319887835

70. Kavanagh T, Mertens DJ, Hamm LF, Beyene J, Kennedy J, Corey $\mathrm{P}$, et al. Prediction of long-term prognosis in 12169 men referred for cardiac rehabilitation. Circulation. (2002) 106:666. doi: 10.1161/01.CIR.0000024413.15949.ED

71. Swank AM, Horton J, Fleg JL, Fonarow GC, Keteyian S, Goldberg L, et al. Modest increase in peak $\mathrm{VO}_{2}$ is related to better clinical outcomes in chronic heart failure patients: results from heart failure and a controlled trial to investigate outcomes of exercise training. Circ Heart Fail. (2012) 5:579-85. doi: 10.1161/CIRCHEARTFAILURE.111.965186

72. Keteyian SJ. Peak aerobic capacity predicts prognosis in patients with coronary heart disease. Am Heart J. (2008) 156:292-300. doi: 10.1016/j.ahj.2008.03.017

73. Uddin J, Zwisler AD, Lewinter C, Moniruzzaman M, Lund K, Tang LH, et al. Predictors of exercise capacity following exercise-based rehabilitation in patients with coronary heart disease and heart failure: a meta-regression analysis. Eur J Prev Cardiol. (2016) 23:683-93. doi: $10.1177 / 2047487315604311$

74. Mitchell BL, Lock MJ, Davison K, Parfitt G, Buckley JP, Eston RG. What is the effect of aerobic exercise intensity on cardiorespiratory fitness in those undergoing cardiac rehabilitation? A systematic review with meta-analysis. Br J Sports Med. (2019) 53:1341. doi: 10.1136/bjsports-2018-099153

75. Vromen T, Kraal JJ, Kuiper J, Spee RF, Peek N, Kemps HM. The influence of training characteristics on the effect of aerobic exercise training in patients with chronic heart failure: a meta-regression analysis. Int J Cardiol. (2016) 208:120-7. doi: 10.1016/j.ijcard.2016.01.207

76. Ismail H, McFarlane JR, Dieberg G, Smart NA. Exercise training program characteristics and magnitude of change in functional capacity of heart failure patients. Int J Cardiol. (2014) 171:62-5. doi: 10.1016/j.ijcard.2013.11.045

77. Sandercock G, Hurtado V, Cardoso F. Changes in cardiorespiratory fitness in cardiac rehabilitation patients: a meta-analysis. Int J Cardiol. (2013) 167:894-902. doi: 10.1016/j.ijcard.2011.11.068

78. Almody M, Ingle L, Sandercock GR. Effects of exercise-based cardiac rehabilitation on cardiorespiratory fitness: a meta-analysis of UK studies. Int J Cardiol. (2016) 221:644-51. doi: 10.1016/j.ijcard.2016.06.101 
79. Liou K, Ho S, Fildes J, Ooi S-Y. High intensity interval versus moderate intensity continuous training in patients with coronary artery disease: a meta-analysis of physiological and clinical parameters. Heart Lung Circ. (2016) 25:166. doi: 10.1016/j.hlc.2015.06.828

80. Elliott AD, Rajopadhyaya K, Bentley DJ, Beltrame JF, Aromataris EC. Interval training versus continuous exercise in patients with coronary artery disease: a meta-analysis. Heart Lung Circ. (2015) 24:149-57. doi: 10.1016/j.hlc.2014.09.001

81. Pattyn N, Coeckelberghs E, Buys R, Cornelissen V, Vanhees L. Aerobic interval training vs. Moderate continuous training in coronary artery disease patients: a systematic review and meta-analysis. Sports Med. (2014) 44:687700. doi: 10.1007/s40279-014-0158-x

82. Xie B, Yan X, Cai X, Li J. Effects of high-intensity interval training on aerobic capacity in cardiac patients: a systematic review with meta-analysis. Biomed Res Int. (2017) 2017:5420840. doi: 10.1155/2017/5420840

83. Way KL, Vidal-Almela S, Moholdt T, Currie KD, Aksetøy IA, Boidin M, et al. Sex differences in cardiometabolic health indicators after HIIT in patients with coronary artery disease. Med Sci Sports Exerc. (2021) 53:1345-1355. doi: 10.1249/MSS.0000000000002596

84. Conraads VM, Pattyn N, De Maeyer C, Beckers PJ, Coeckelberghs E, Cornelissen VA, et al. Aerobic interval training and continuous training equally improve aerobic exercise capacity in patients with coronary artery disease: the SAINTEX-CAD study. Int J Cardiol. (2015) 179:203-10. doi: 10.1016/j.ijcard.2014.10.155

85. Moholdt TT, Amundsen BH, Rustad LA, Wahba A, Løvø KT, Gullikstad LR, et al. Aerobic interval training versus continuous moderate exercise after coronary artery bypass surgery: a randomized study of cardiovascular effects and quality of life. Am Heart J. (2009) 158:1031-7. doi: 10.1016/j.ahj.2009.10.003

86. Haykowsky MJ, Timmons MP, Kruger C, McNeely M, Taylor DA, Clark AM. Meta-analysis of aerobic interval training on exercise capacity and systolic function in patients with heart failure and reduced ejection fractions. Am J Cardiol. (2013) 111:1466-9. doi: 10.1016/j.amjcard.2013.01.303

87. Smart NA, Dieberg G, Giallauria F. Intermittent versus continuous exercise training in chronic heart failure: a meta-analysis. Int J Cardiol. (2013) 166:352-8. doi: 10.1016/j.ijcard.2011.10.075

88. Ellingsen $\varnothing$, Halle M, Conraads VM, Støylen A, Dalen H, Delagardelle $\mathrm{C}$, et al. High intensity interval training in heart failure patients with reduced ejection fraction. Circulation. (2017) 135:839-49. doi: 10.1161/CIRCULATIONAHA.116.022924

89. Mueller S, Winzer EB, Duvinage A, Gevaert AB, Edelmann F, Haller B, et al. Effect of high-intensity interval training, moderate continuous training, or guideline-based physical activity advice on peak oxygen consumption in patients with heart failure with preserved ejection fraction: a randomized clinical trial. JAMA. (2021) 325:542-51. doi: 10.1001/jama.2020.26812

90. Jensen BE, Fletcher BJ, Rupp JC, Fletcher GF, Lee JY, Oberman A. Training Level Comparison Study: effect of high and low intensity exercise on ventilatory threshold in men with coronary artery disease. J Cardiopulm Rehabil. (1996) 16:227-32. doi: 10.1097/00008483-199607000-00003

91. Quindry JC, Franklin BA, Chapman M, Humphrey R, Mathis S. Benefits and risks of high-intensity interval training in patients with coronary artery disease. Am J Cardiol. (2019) 123:1370-7. doi: 10.1016/j.amjcard.2019.01.008

92. Molmen-Hansen HE, Stolen T, Tjonna AE, Aamot IL, Ekeberg IS, Tyldum GA, et al. Aerobic interval training reduces blood pressure and improves myocardial function in hypertensive patients. Eur J Prev Cardiol. (2012) 19:151-60. doi: 10.1177/1741826711400512

93. Iellamo F, Caminiti G, Sposato B, Vitale C, Massaro M, Rosano G, et al. Effect of High-Intensity interval training versus moderate continuous training on 24-h blood pressure profile and insulin resistance in patients with chronic heart failure. Intern Emerg Med. (2014) 9:547-52. doi: 10.1007/s11739-013-0980-4

94. Ramos JS, Dalleck LC, Tjonna AE, Beetham KS, Coombes JS. The impact of high-intensity interval training versus moderate-intensity continuous training on vascular function: a systematic review and meta-analysis. Sports Med. (2015) 45:679-92. doi: 10.1007/s40279-015-0321-Z

95. Keating S, Johnson N, Mielke G, Coombes J. A systematic review and metaanalysis of interval training versus moderate-intensity continuous training on body adiposity. Obesity Rev. (2017) 18 943-64. doi: 10.1111/obr.12536
96. Dun Y, Thomas RJ, Medina-Inojosa JR, Squires RW, Huang H, Smith JR, et al. High-intensity interval training in cardiac rehabilitation: impact on fat mass in patients with myocardial infarction. Mayo Clin Proc. (2019) 94:1718-30. doi: 10.1016/j.mayocp.2019.04.033

97. Taylor JL, Holland DJ, Mielke GI, Bailey TG, Johnson NA, Leveritt MD, et al. Effect of high intensity interval training on visceral and liver fat in cardiac rehabilitation: a randomised controlled trial. Obesity. (2020) 28:1245-53. doi: 10.1002/oby.22833

98. Cornelis J, Beckers P, Taeymans J, Vrints C, Vissers D. Comparing exercise training modalities in heart failure: a systematic review and meta-analysis. Int J Cardiol. (2016) 221:867-76. doi: 10.1016/j.ijcard.2016.07.105

99. Pattyn N, Vanhees L, Cornelissen VA, Coeckelberghs E, De Maeyer C, Goetschalckx K, et al. The long-term effects of a randomized trial comparing aerobic interval versus continuous training in coronary artery disease patients: 1-year data from the SAINTEX-CAD study. Eur J Prev Cardiol. (2016) 23:1154-64. doi: 10.1177/2047487316631200

100. Taylor JL, Coombes JS, Holland DJ, Keating SE, Green DJ, Bailey TG. Short and long term effects of exercise intensity on conduit artery function in cardiac rehabilitation patients: (1642). May 30 2:00 PM - 2:15 PM. Med Sci Sports Exerc. (2019) 51:449. doi: 10.1249/01.mss.0000561843.86325.1

101. Taylor JL, Keating SE, Holland DJ, Finlayson G, King NA, Gomersall SR, et al. High intensity interval training does not result in short- or long-term dietary compensation in cardiac rehabilitation: results from the FITR heart study. Appetite. (2021) 158:105021. doi: 10.1016/j.appet.2020.105021

102. Del Buono MG, Arena R, Borlaug BA, Carbone S, Canada JM, Kirkman DL, et al. Exercise intolerance in patients with heart failure: JACC state-of-the-art review. J Am Coll Cardiol. (2019) 73:2209-25. doi: 10.1016/j.jacc.2019.01.072

103. Olson TP, Snyder EM, Johnson BD. Exercise-disordered breathing in chronic heart failure. Exerc Sport Sci Rev. (2006) 34:194-201. doi: 10.1249/01.jes.0000240022.30373.a2

104. Smith JR, Berg JD, Curry TB, Joyner MJ, Olson TP. Respiratory muscle work influences locomotor convective and diffusive oxygen transport in human heart failure during exercise. Physiol Rep. (2020) 8:e14484. doi: 10.14814/phy2.14484

105. Olson TP, Johnson BD, Borlaug BA. Impaired pulmonary diffusion in heart failure with preserved ejection fraction. JACC Heart failure. (2016) 4:490-8. doi: 10.1016/j.jchf.2016.03.001

106. Dempsey JA, Amann M, Romer LM, Miller JD. Respiratory system determinants of peripheral fatigue and endurance performance. Med Sci Sports Exerc. (2008) 40:457-61. doi: 10.1249/MSS.0b013e31815f8957

107. Tasoulis A, Papazachou O, Dimopoulos S, Gerovasili V, Karatzanos E, Kyprianou T, et al. Effects of interval exercise training on respiratory drive in patients with chronic heart failure. Respir Med. (2010) 104:1557-65. doi: 10.1016/j.rmed.2010.03.009

108. Dunham C, Harms CA. Effects of high-intensity interval training on pulmonary function. Eur J Appl Physiol. (2012) 112:3061-8. doi: 10.1007/s00421-011-2285-5

109. Guazzi M, Reina G, Tumminello G, Guazzi MD. Improvement of alveolar-capillary membrane diffusing capacity with exercise training in chronic heart failure. J Appl Physiol. (2004) 97:1866-73. doi: 10.1152/japplphysiol.00365.2004

110. Karlsen T, Aamot I-L, Haykowsky M, Rognmo Ø. High intensity interval training for maximizing health outcomes. Prog Cardiovasc Dis. (2017) 60:6777. doi: 10.1016/j.pcad.2017.03.006

111. Lundby C, Montero D, Joyner M. Biology of $\mathrm{VO}(2)$ max: looking under the physiology lamp. Acta Physiol (Oxf). (2017) 220:218-28. doi: 10.1111/apha.12827

112. Levine $\mathrm{BD} \cdot \mathrm{VO}_{2}$ max: what do we know, and what do we still need to know? $J$ Physiol. (2008). 586:25-34. doi: 10.1113/jphysiol.2007.147629

113. Hambrecht R, Gielen S, Linke A, Fiehn E, Yu J, Walther C, et al. Effects of exercise training on left ventricular function and peripheral resistance in patients with chronic heart failure: a randomized trial. JAMA. (2000) 283:3095-101. doi: 10.1001/jama.283.23.3095

114. Piña IL, Apstein CS, Balady GJ, Belardinelli R, Chaitman BR, Duscha BD, et al. Exercise and heart failure. Circulation. (2003) 107:1210-25. doi: 10.1161/01.CIR.0000055013.92097.40

115. Helgerud JAN, HØYdal K, Wang E, Karlsen T, Berg P, Bjerkaas $\mathrm{M}$, et al. Aerobic high-intensity intervals improve $\mathrm{VO}_{2} \max$ more 
than moderate training. Med Sci Sports Exerc. (2007) 39:665-71. doi: 10.1249/mss.0b013e3180304570

116. Matsuo T, Saotome K, Seino S, Shimojo N, Matsushita A, Iemitsu $M$, et al. Effects of a low-volume aerobic-type interval exercise on $\mathrm{VO}_{2} \max$ and cardiac mass. Med Sci Sports Exerc. (2014) 46:42-50. doi: 10.1249/MSS.0b013e3182a38da8

117. Fu TC, Yang NI, Wang CH, Cherng WJ, Chou SL, Pan TL, et al. Aerobic interval training elicits different hemodynamic adaptations between heart failure patients with preserved and reduced ejection fraction. Am J Phys Med Rehabil. (2016) 95:15-27. doi: 10.1097/PHM.0000000000000312

118. Iellamo F, Manzi V, Caminiti G, Vitale C, Castagna C, Massaro M, et al. Matched dose interval and continuous exercise training induce similar cardiorespiratory and metabolic adaptations in patients with heart failure. Int J Cardiol. (2013) 167:2561-5. doi: 10.1016/j.ijcard.2012. 06.057

119. Green DJ, Hopman MT, Padilla J, Laughlin MH, Thijssen DH. Vascular adaptation to exercise in humans: role of hemodynamic stimuli. Physiol Rev. (2017) 97:495-528. doi: 10.1152/physrev.00014.2016

120. Anderson TJ, Uehata A, Gerhard MD, Meredith IT, Knab S, Delagrange $\mathrm{D}$, et al. Close relation of endothelial function in the human coronary and peripheral circulations. J Am Coll Cardiol. (1995) 26:1235-41. doi: 10.1016/0735-1097(95)00327-4

121. Barnes JN, Schmidt JE, Nicholson WT, Joyner MJ. Cyclooxygenase inhibition abolishes age-related differences in cerebral vasodilator responses to hypercapnia. J Appl Physiol (1985). (2012) 112:1884-90. doi: 10.1152/japplphysiol.01270.2011

122. Calverley TA, Ogoh S, Marley CJ, Steggall M, Marchi N, Brassard P, et al. HIITing the brain with exercise; mechanisms, consequences and practical recommendations. J Physiol. (2020) 598:2513-30. doi: 10.1113/JP275021

123. Thijssen DHJ, Dawson EA, Black MA, Hopman MTE, Cable NT, Green DJ. Brachial artery blood flow responses to different modalities of lower limb exercise. Med Sci Sports Exerc. (2009) 41:1072-9. doi: 10.1249/MSS.0b013e3181923957

124. Haykowsky MJ, Brubaker PH, Stewart KP, Morgan TM, Eggebeen J, Kitzman DW. Effect of endurance training on the determinants of peak exercise oxygen consumption in elderly patients with stable compensated heart failure and preserved ejection fraction. J Am Coll Cardiol. (2012) 60:120-8. doi: 10.1016/j.jacc.2012.02.055

125. Lundby C, Jacobs RA. Adaptations of skeletal muscle mitochondria to exercise training. Exp Physiol. (2016) 101:17-22. doi: 10.1113/EP085319

126. MacInnis MJ, Gibala MJ. Physiological adaptations to interval training and the role of exercise intensity. J Physiol. (2017) 595:2915-30. doi: 10.1113/JP273196

127. Egan B, Zierath JR. Exercise metabolism and the molecular regulation of skeletal muscle adaptation. Cell Metabolism. (2013) 17:162-84. doi: 10.1016/j.cmet.2012.12.012

128. Joyner MJ, Coyle EF. Endurance exercise performance: the physiology of champions. J Physiol. (2008) 586:35-44. doi: 10.1113/jphysiol.2007.143834

129. Schjerve IE, Tyldum GA, Tjønna AE, Stølen T, Loennechen JP, Hansen HEM, et al. Both aerobic endurance and strength training programmes improve cardiovascular health in obese adults. Clin Sci. (2008) 115:283-93. doi: $10.1042 / C S 20070332$

130. Gliemann L. Training for skeletal muscle capillarization: a Janus-faced role of exercise intensity? Eur J Appl Physiol. (2016) 116:1443-4. doi: 10.1007/s00421-016-3419-6

131. Daussin FN, Zoll J, Dufour SP, Ponsot E, Lonsdorfer-Wolf E, Doutreleau S, et al. Effect of interval versus continuous training on cardiorespiratory and mitochondrial functions: relationship to aerobic performance improvements in sedentary subjects. Am J Physiol Regul Integr Compar Physiol. (2008) 295:R264-72. doi: 10.1152/ajpregu.00875.2007

132. Hoier B, Passos M, Bangsbo J, Hellsten Y. Intense intermittent exercise provides weak stimulus for vascular endothelial growth factor secretion and capillary growth in skeletal muscle. Exp Physiol. (2013) 98:585-97. doi: 10.1113/expphysiol.2012.067967

133. Simoneau JA, Lortie G, Boulay MR, Marcotte M, Thibault MC, Bouchard C. Human skeletal muscle fiber type alteration with high-intensity intermittent training. Eur J Appl Physiol Occup Physiol. (1985) 54:250-3. doi: $10.1007 / \mathrm{BF} 00426141$
134. Hambrecht R, Fiehn E, Yu J, Niebauer J, Weigl C, Hilbrich L, et al. Effects of endurance training on mitochondrial ultrastructure and fiber type distribution in skeletal muscle of patients with stable chronic heart failure. J Am Coll Cardiol. (1997) 29:1067-73. doi: 10.1016/S0735-1097(97) 00015-6

135. Tan R, Nederveen JP, Gillen JB, Joanisse S, Parise G, Tarnopolsky $\mathrm{MA}$, et al. Skeletal muscle fiber-type-specific changes in markers of capillary and mitochondrial content after low-volume interval training in overweight women. Physiol Rep. (2018) 6:e13597. doi: 10.14814/phy2. 13597

136. Ribeiro PAB, Boidin M, Juneau M, Nigam A, Gayda M. High-intensity interval training in patients with coronary heart disease: Prescription models and perspectives. Ann Phys Rehabil Med. (2016) 60:50-7. doi: 10.1016/j.rehab.2016.04.004

137. Gayda M, Ribeiro PA, Juneau M, Nigam A. Comparison of different forms of exercise training in patients with cardiac disease: where does high-intensity interval training fit? Can J Cardiol. (2016) 32: 485-94. doi: 10.1016/j.cjca.2016.01.017

138. Williams CJ, Gurd BJ, Bonafiglia JT, Voisin S, Li Z, Harvey N, et al. A multi-center comparison of $\mathrm{VO}_{2}$ peak trainability between interval training and moderate intensity continuous training. Front Physiol. (2019) 10:19. doi: 10.3389/fphys.2019.00019

139. Milanovic Z, Sporis G, Weston M. Effectiveness of high-intensity interval training (HIT) and continuous endurance training for vo2max improvements: a systematic review and meta-analysis of controlled trials. Sports Med. (2015) 45:1469-81. doi: 10.1007/s40279-0150365-0

140. Bacon AP, Carter RE, Ogle EA, Joyner MJ. $\mathrm{VO}_{2} \max$ trainability and high intensity interval training in humans: a meta-analysis. PLoS ONE. (2013) 8:e73182. doi: 10.1371/journal.pone.0073182

141. Thompson PD, Franklin BA, Balady GJ, Blair SN, Corrado D, Estes $\mathrm{NA}$, et al. Exercise and acute cardiovascular events placing the risks into perspective: a scientific statement from the American Heart Association council on nutrition, physical activity, and metabolism and the council on clinical cardiology. Circulation. (2007) 115:2358-68. doi: 10.1161/CIRCULATIONAHA.107.181485

142. Mittleman MA, Maclure M, Tofler GH, Sherwood JB, Goldberg RJ, Muller JE. Triggering of acute myocardial infarction by heavy physical exertion. Protection against triggering by regular exertion. Determinants of myocardial infarction onset study investigators. $N$ Engl $J$ Med. (1993) 329:1677-83.

143. Haykowsky MJ, Daniel KM, Bhella PS, Sarma S, Kitzman DW. Heart failure: exercise-based cardiac rehabilitation: who, when, and how intense? Can J Cardiol. (2016) 32(10 Suppl 2):S382-7. doi: 10.1016/j.cjca.2016.06.001

144. Wewege Michael A, Ahn D, Yu J, Liou K, Keech A. High-Intensity interval training for patients with cardiovascular disease-is it safe? A systematic review. J Am Heart Assoc. (2018) 7:e009305. doi: 10.1161/JAHA.118.009305

145. Koufaki P, Mercer TH, George KP, Nolan J. Low-volume high-intensity interval training vs continuous aerobic cycling in patients with chronic heart failure: a pragmatic randomised clinical trial of feasibility and effectiveness. $J$ Rehabil Med. (2014) 46:348-56. doi: 10.2340/16501977-1278

146. Pelliccia A, Sharma S, Gati S, Bäck M, Börjesson M, Caselli S, et al. 2020 ESC Guidelines on sports cardiology and exercise in patients with cardiovascular disease: the task force on sports cardiology and exercise in patients with cardiovascular disease of the European Society of Cardiology (ESC). Eur Heart J. (2021) 42:17-96. doi: 10.1093/eurheartj/ehaa605

147. Iellamo F, Volterrani M. Letter by iellamo and volterrani regarding article, "high-intensity interval training in patients with heart failure with reduced ejection fraction". Circulation. (2017) 136:605-6. doi: 10.1161/CIRCULATIONAHA.117.028249

148. Aamot IL, Forbord SH, Karlsen T, Stoylen A. Does rating of perceived exertion result in target exercise intensity during interval training in cardiac rehabilitation? A study of the Borg scale versus a heart rate monitor. J Sci Med Sport. (2014) 17:541-5. doi: 10.1016/j.jsams.2013.07.019

149. Bull FC, Al-Ansari SS, Biddle S, Borodulin K, Buman MP, Cardon $\mathrm{G}$, et al. World health organization 2020 guidelines on physical activity and sedentary behaviour. Br J Sports Med. (2020) 54:1451. doi: 10.1136/bjsports-2020-102955 
150. Piercy KL, Troiano RP, Ballard RM, Carlson SA, Fulton JE, Galuska DA, et al. The physical activity guidelines for americans. JAMA. (2018) 320:2020-8. doi: 10.1001/jama.2018.14854

151. Squires RW, Kaminsky LA, Porcari JP, Ruff JE, Savage PD, Williams MA. Progression of Exercise Training in Early Outpatient Cardiac Rehabilitation: AN OFFICIAL STATEMENT FROM THE AMERICAN ASSOCIATION OF CARDIOVASCULAR AND PULMONARY REHABILITATION. J Cardiopulm Rehabil Prev. (2018) 38:139-46. doi: 10.1097/HCR.0000000000000337

152. Hambrecht R, Niebauer J, Marburger C, Grunze M, Kälberer B, Hauer K, et al. Various intensities of leisure time physical activity in patients with coronary artery disease: effects on cardiorespiratory fitness and progression of coronary atherosclerotic lesions. J Am Coll Cardiol. (1993) 22:468-47. doi: 10.1016/0735-1097(93)90051-2

153. Physical Activity Guidelines Advisory Committee. 2018 Physical Activity Guidelines Advisory Committee Scientific Report. Washington, DC: US Department of Health and Human Services (2018).

154. Kokkinos P, Kaminsky LA, Arena R, Zhang J, Myers J. New generalized equation for predicting maximal oxygen uptake (from the fitness registry and the importance of exercise national database). Am J Cardiol. (2017) 120:688-92. doi: 10.1016/j.amjcard.2017.05.037

155. Kokkinos P, Kaminsky LA, Arena R, Zhang J, Myers J. A new generalized cycle ergometry equation for predicting maximal oxygen uptake: the fitness registry and the importance of exercise national database (FRIEND). Eur J Prev Cardiol. (2018) 25:1077-82. doi: 10.1177/20474873187 72667

156. Ainsworth BE, Haskell WL, Herrmann SD, Meckes N, Bassett DR Jr, Tudor-Locke C, et al. 2011 Compendium of physical activities: a second update of codes and MET values. Med Sci Sports Exerc. (2011). 43:1575-81. doi: 10.1249/MSS.0b013e31821ece12

157. Iellamo F, Manzi V, Caminiti G, Sposato B, Massaro M, Cerrito A, et al. Dose-response relationship of baroreflex sensitivity and heart rate variability to individually-tailored exercise training in patients with heart failure. Int $J$ Cardiol. (2013) 166:334-9. doi: 10.1016/j.ijcard.2011.10.082
158. Dun Y, Smith JR, Liu S, Olson TP. High-intensity interval training in cardiac rehabilitation. Clin Geriatr Med. (2019) 35:469-87. doi: 10.1016/j.cger.2019.07.011

159. Keteyian SJ, Squires RW, Ades PA, Thomas RJ. Incorporating patients with chronic heart failure into outpatient cardiac rehabilitation: practical recommendations for exercise and self-care counselinga clinical review. I Cardiopulm Rehabil Prev. (2014) 34:223-32. doi: 10.1097/HCR.0000000000000073

160. Ades PA, Keteyian SJ, Balady GJ, Houston-Miller N, Kitzman DW, Mancini $\mathrm{DM}$, et al. Cardiac rehabilitation exercise and self-care for chronic heart failure. JACC Heart Fail. (2013) 1:540-7. doi: 10.1016/j.jchf.2013.09.002

161. Arena R, Myers J, Williams MA, Gulati M, Kligfield P, Balady GJ, et al. Assessment of functional capacity in clinical and research settings. Circulation. (2007) 116:329-43. doi: 10.1161/CIRCULATIONAHA.106.184461

Conflict of Interest: The authors declare that the research was conducted in the absence of any commercial or financial relationships that could be construed as a potential conflict of interest.

Publisher's Note: All claims expressed in this article are solely those of the authors and do not necessarily represent those of their affiliated organizations, or those of the publisher, the editors and the reviewers. Any product that may be evaluated in this article, or claim that may be made by its manufacturer, is not guaranteed or endorsed by the publisher.

Copyright $\odot 2021$ Taylor, Bonikowske and Olson. This is an open-access article distributed under the terms of the Creative Commons Attribution License (CC BY). The use, distribution or reproduction in other forums is permitted, provided the original author(s) and the copyright owner(s) are credited and that the original publication in this journal is cited, in accordance with accepted academic practice. No use, distribution or reproduction is permitted which does not comply with these terms. 